\title{
Urbanización, crecimiento y expectativas del planeamiento urbanístico en las áreas urbanas intermedias españolas (1981-2018)
}

\author{
Urbanisation, growth, and expectations for urban planning \\ in Spanish intermediate cities (1981-2018)
}

\author{
Carme Bellet Sanfeliu ${ }^{1}$ \\ Gonzalo Andrés López ${ }^{2 *}$ (iD)
}

\section{Resumen}

En los últimos cuarenta años, en las ciudades se ha producido una acusada fase de crecimiento y expansión, culminada con el "boom" inmobiliario de la denominada "década prodigiosa" del urbanismo español (1997-2007). En este proceso, las áreas urbanas articuladas por ciudades medias han protagonizado los crecimientos relativos más notables del sistema urbano en España, muy por encima de lo que realmente representan en población, parque de viviendas y superficie urbanizada. Como consecuencia de ello, estas ciudades han modificado su estructura tradicionalmente compacta y relativamente densa, generándose nuevas formas definidas por la fragmentación y el intensivo consumo de suelo en las periferias. Se ha consolidado así un modelo de ciudad diseñado por un planeamiento urbanístico convertido en instrumento para proyectar en el territorio las dinámicas del crecimiento económico. Desde el año 2008 se ha abierto un claro proceso de ralentización de esta expansión, lo que invita a considerar un cambio de ciclo y, en consecuencia, la generación de un nuevo modelo de ciudad más racional y sostenible. Sin embargo, el análisis del planeamiento general vigente en estas ciudades obliga a reconsiderar esta hipótesis, ya que las expectativas de crecimiento continúan siendo muy elevadas y el modelo urbano sigue centrado en la extensión y la propuesta de grandes sectores de nuevo suelo urbanizable.

Palabras clave: Ciudades medias; planificación urbana; modelo urbano insostenible; urbanismo expansivo; expectativas de crecimiento

\begin{abstract}
Spanish cities have experienced a phase of marked growth and expansion over the last 40 years. This culminated in a property boom at the end of what came to be known as the 'prodigious decade' of Spanish urban development (1997-2007). Within this process, urban areas articulated by medium-sized cities underwent the most notable relative growth in the urban system. As a result, intermediate cities modified their traditionally compact and relatively dense structures and took on new forms that were defined by fragmentation and the intensive consumption of land in the urban periphery. In this way, an urban planning city model was consolidated which served as an instrument for projecting the dynamics of economic growth in each territory. However, since 2008, there has been a noticeable slowing of this expansion. This suggests a change of cycle and, in consequence, the creation of a new and more rational and sustainable city model. However, an analysis of the Master Plans currently applied in these cities

1 Universitat de Lleida. carme.bellet@udl.cat

2 Universidad de Burgos. gandres@ubu.es. * Autor para correspondencia


has revealed the need to reconsider this hypothesis, as expectations of growth remain high, and the city model continues to focus on expansion and proposals for the development of large areas of new land.

Keywords: Medium-sized cities; urban planning; unsustainable urban model; expansive urbanism; expectations for growth.

\section{Introducción}

La vinculación directa del crecimiento urbano con las fases de expansión económica viene siendo una relación recurrente durante las últimas décadas en España. Desde mediados del siglo XX, se han ido articulando profundas vinculaciones entre el crecimiento económico, el hecho urbanizador, el progreso del sector de la construcción y la dinámica del mercado inmobiliario (Górgolas, 2017; López y Rodríguez, 2010). Más aún, estas vinculaciones se han ido retroalimentando, puesto que todos los períodos de crecimiento económico se han sostenido igualmente en el avance de la intensificación de la urbanización del territorio a través de la producción de infraestructuras, suelo urbano y artefactos urbanos. Esta intensa relación ha llevado a algunos autores a hablar del capitalismo inmobiliario español (Naredo, 2010). En la práctica, este proceso ha derivado en acciones de extracción y captación de rentas del suelo generadas por el hecho urbanizador (Vives y Rullán, 2014; Capel, 2013b).

Las expansiones inmobiliarias en el tiempo se han producido cuando las expectativas de la plusvalía generada por la actividad han resultado superiores a las de otras actividades económicas (Lois, Piñeira y Vives, 2016; Méndez, 2018). Esas expansiones cíclicas de la actividad inmobiliaria/urbanizadora van imprimiendo su particular huella espacial, materializando paisajes urbanos específicos de cada etapa que en cada momento son avalados por una legislación y política urbanística determinada (Bellet, 2020). Se produce así una evidente asociación entre el proceso económico, el planeamiento urbano y las dinámicas del proceso urbanizador. De esta forma, el planeamiento urbano no sólo expresa las condiciones bajo las cuales se produce la urbanización del territorio, sino que, en el marco del capitalismo inmobiliario español, deviene en uno de los mecanismos para vehicular las expectativas de crecimiento basadas en el consumo y urbanización del suelo. (Naredo, 1996 y 2010; Calderón y García, 2017).

Se ha generado así en la historia reciente del urbanismo en el país una manifiesta dependencia del modelo urbano respecto a las directrices generadas por el capitalismo inmobiliario. La ciudad ha sido construida en virtud de un guión definido por las pautas que ha ido marcando en el tiempo el negocio en torno a la construcción y venta de vivienda y suelo. De esta forma, se ha consolidado en la práctica un urbanismo cautivo del crecimiento económico y directamente relacionado con la evolución de los mercados inmobiliarios — un diseño de ciudad a demanda del ciclo económico- (García, Serrano y Espejo, 2020). Se trata de una estrategia bien expresiva de los intereses del mercado por controlar un urbanismo que se ha demostrado endeble y falto de un modelo racional y sostenible para construir ciudades equilibradas (Górgolas, 2019a). Gaja ha llegado a denominar tal circunstancia como la del "urbanismo concesional", en cuanto a que el proyecto urbano queda así en manos de la iniciativa privada, se pliega a las cuestiones técnico-instrumentales y fomenta la dispersión territorial, con actuaciones urbanísticas de muy baja densidad y clara disfuncionalidad (Gaja, 2015).

Lo cierto es que este marco - un urbanismo definido por el crecimiento económico y vinculado a los intereses del mercado- ha conllevado en las últimas décadas un significativo proceso de urbanización insostenible que ha modificado sustancialmente el paisaje y la estructura urbana precedente. En efecto, desde 1980 y fundamentalmente entre 1997 y hasta la crisis de 2007, se ha producido en España un intenso proceso de urbanización dispersa que ha afectado a todo el país (Rodríguez, 2006). Se trata de dinámicas recientes relacionadas con la creciente artificialización del suelo y el "boom" inmobiliario (Fernández y Corbelle, 2017; Olazabal y Bellet, 2018; Pozueta, Lamíquiz, Higueras y Benito, 2019). Tras las notables dinámicas de urbanización acontecidas en los años sesenta y setenta del pasado siglo XX, en las décadas posteriores ha cambiado no sólo la intensidad o ritmo del proceso, sino sobre todo el carácter de la urbanización. La extensión y la consolidación de áreas de mayor consumo de suelo ha incidido en la reducción de la compacidad de las ciudades, especialmente en las periferias de las áreas urbanas (Monclús, 1998; Olazabal y Bellet, 2019). Estos procesos se intensificaron considerablemente durante el "boom" inmobiliario (1997-2007), suponiendo un antes y un después para el conjunto del paisaje urbano español y afectando a amplias áreas del territorio (Burriel, 2008; Gaja, 2008).

De forma general, si se estudia y analiza con detenimiento la evolución demográfica de las ciudades y se contrapone al ritmo de crecimiento del número de viviendas construidas y a la superficie de suelo 
urbanizado, se pone de manifiesto un profundo desajuste en el modelo de crecimiento. En las últimas décadas, la población de las áreas urbanas, cuando no ha decrecido, se ha incrementado en ratios considerablemente inferiores a los que lo ha hecho la superficie urbanizada o el número de viviendas. Construcción de infraestructuras con un vasto consumo de suelo, grandes desarrollos de suelo para viviendas, nuevos equipamientos públicos y grandes conjuntos terciarios, suelos industriales y, en fin, nuevas periferias complejas han definido el modelo de la ciudad del "todo urbanizable" (Calderón, 2004).

Desde luego, un factor determinante de dicha situación ha sido el de la previa clasificación de amplias bolsas de suelo potencialmente urbanizable, en expectativa de desarrollo, a la espera de las inversiones necesarias para poder materializar su urbanización. El planeamiento urbano ha contribuido claramente a generar una ciudad definida por la extensión y la dispersión, consolidando ese modelo de ciudad dispersa (Calderón y García, 2017 y 2018; Romero, Brandis y Melo, 2015). Algunos autores han considerado que, superada la recesión económica, se ha abierto la crisis de este modelo urbano, considerando que la ciudad dispersa representa, "per se", un esquema de anti-ciudad o anti-polis, apartándose del modelo tradicional de urbanización (Capel, 2013a).

En este contexto, este trabajo pretende reflexionar sobre la contradicción de este modelo de ciudad predominante en las últimas décadas, analizando e interrelacionando las dinámicas de urbanización con las expectativas generadas por el planeamiento urbanístico. Y, en concreto, el objetivo de la contribución se centra en estudiar de qué forma se ha producido este fenómeno en las áreas urbanas articuladas por ciudades medias. Este tipo de ciudades presentan los crecimientos relativos más notables del sistema urbano entre 1981 y 2018, muy por encima de lo que realmente suponen en población, parque de viviendas y superficie urbanizada (Olazabal, 2018; Martínez, García y Escudero, 2020). En las ciudades medias, se han intensificado las dinámicas de urbanización vinculadas a las estrategias de crecimiento planteadas y alentadas por la planificación urbanística municipal. Lo cierto es que este tipo de ciudades se han convertido en receptores de buena parte de los crecimientos del sistema urbano, asumiendo un papel estratégico en la articulación territorial, incluso en el contexto de los conjuntos metropolitanos y las grandes regiones urbanas (Adam, 2006). En estas ciudades la transformación ha sido de tal intensidad que las estructuras tradicionalmente compactas y relativamente densas han quedado desdibujadas por la fragmentación, la dispersión y el intensivo consumo de suelo en las periferias (Olazabal y Bellet, 2019; Cebrián, 2007 y 2013).

Desde esta perspectiva, el objetivo de este trabajo es doble: en primer lugar, se trata de caracterizar los procesos de urbanización de las ciudades medias españolas y sus áreas urbanas en las últimas décadas -en el periodo que transcurre entre el comienzo de los años ochenta y la actualidad-; y, en segundo lugar, se plantea cuantificar las fuertes expectativas de crecimiento que el planeamiento vigente mantiene en la actualidad, al objeto de cuestionar el modelo urbano que este plantea y contrastar tal situación con el nuevo contexto de la desaceleración de la expansión. Las expectativas de crecimiento del planeamiento se plantearon en un contexto de fuerte expansión urbana alimentada claramente por las dinámicas liberalizadoras del mercado del suelo. Y pese a los discursos académicos y políticos sobre la necesidad de replanteamiento del modelo de ciudad y urbano que tantas consecuencias negativas ha comportado para el territorio y el conjunto de la sociedad, una vez llegada la crisis, no parece que todo ello se refleje en las expectativas de crecimiento del planeamiento vigente. La estrategia urbanística del crecimiento expansivo vinculada al ciclo económico alcista no parece haber sido modificada en la planificación urbana lo que genera una evidente contradicción entre el nuevo contexto urbano impuesto por la crisis y los modelos de ciudad que la mayor parte de Planes Generales de Ordenación Urbana todavía reflejan. El trabajo interrelaciona ambas cuestiones en las ciudades medias, analizando primero la reciente evolución de la dinámica urbanizadora y considerando después la previsión de expectativa de crecimiento de la planificación municipal actual. Los resultados de este ejercicio generan una discusión sobre el modelo de urbanización, lo que se traduce a su vez en una conclusión relativa a la falta de sostenibilidad del planteamiento de ciudad que todavía pervive en la planificación urbana.

\section{Metodología}

Para abordar tales objetivos, a partir de las hipótesis formuladas, la investigación se ha desarrollado mediante un método deductivo, utilizando diversa información y desarrollando un tratamiento analítico de los datos mediante técnicas estadísticas y cartográficas. La información utilizada se ha centrado en el manejo de cuatro series de variables (población, vivienda, suelo urbanizado y potenciales de crecimiento 
(suelo y viviendas) según el planeamiento urbanístico municipal vigente) aplicadas a un objeto de estudio definido (las áreas urbanas articuladas por ciudades medias en España). En relación con este planteamiento metodológico, cabe realizar algunas precisiones.

En primer lugar, resulta necesario identificar correctamente el ámbito territorial del estudio, centrado en las ciudades medias. En España, el umbral de población de las ciudades medias, según la Ley 7/85 de Bases de Régimen Local, estaría entre los 20.000 y los 100.000 habitantes. Sin embargo, los estudios académicos y los estudios técnicos territoriales amplían este intervalo que, en general, se sitúa entre los 50.000 y los 250.000 habitantes. Además, debe aclararse que, más allá de los municipios centrales, el objeto de estudio son las aglomeraciones o áreas urbanas que se han consolidado en el entorno de estas ciudades en España. Sobre este particular, aunque diversos autores han trabajado en propuestas de delimitación (López Trigal, 2014; Miramontes y Viera, 2016; Gómez, Vieira y Hernández. 2020) y existen también algunas divisiones de carácter funcional (INE, Urban Audit), no hay una clasificación oficial predominante y que esté completamente aceptada. Ante tal circunstancia, se ha tomado como referencia la propuesta de delimitación establecida en el Atlas Estadístico de las Áreas Urbanas del Ministerio de Transportes, Movilidad y Agenda Urbana (MTMA, 2018a) .

A partir de esta delimitación, el trabajo se ha planteado distinguiendo entre dos tipos básicos de áreas urbanas. Por un lado, aquel grupo configurado por las grandes áreas urbanas (GAU), articuladas por grandes metrópolis o grandes ciudades que suman más de 250.000 habitantes y que cuentan en el conjunto de su área urbana con más de 400.000 personas. Se trata de las siguientes 20 áreas urbanas: Madrid, Barcelona, Valencia, Sevilla, Bilbao, Málaga, Gijón-Oviedo, Zaragoza, Alicante, Cádiz-Jerez de la Frontera, Murcia, Vigo, Las Palmas de Gran Canaria, Palma de Mallorca, Granada, Santa Cruz Tenerife, La Coruña, San Sebastián, Valladolid y Córdoba. Por otro lado, las denominadas como MAU —áreas urbanas articuladas por ciudades medias-, cuya ciudad o ciudades "centrales" alojan entre 50.000 y 250.000 habitantes y, cuyo conjunto de población en el área no supera los 400.000 habitantes ${ }^{4}$. Este conjunto de MAU compone el objeto de estudio central, que se concreta en 60 áreas urbanas articuladas por 66 ciudades medias, siendo 6 de las áreas bipolares: Tarragona-Reus; Santander-Torrelavega; Castellón de la Plana-Vila-Real; Algeciras-La Línea de la Concepción; Marbella-Estepona; Santa Lucia de Tirajana-San Bartolomé. El conjunto de las 60 áreas está compuesto por 245 municipios (sobre un total de 8.131 municipios) que comprenden una superficie de $24.172 \mathrm{~km}^{2}$ y alojan un total de 8.110 .564 de habitantes, lo que supone un $17,5 \%$ de la población del conjunto del país y el 21\% de la población urbana (Padrón Municipal, INE, 2018). El conjunto de las 80 áreas urbanas y su división en ambas categorías —GAU y MAU— según la población en 2018 se puede observar en la Figura 1.

El estudio se centra en la consideración de las dinámicas y expectativas de crecimiento de las MAU en España, si bien para ello se precisa también del análisis del conjunto del sistema urbano para contextualizarlo. Para ello, se trabaja igualmente la información estadística de las 20 GAU. El estudio contempla además un análisis en distintas escalas para el que se han delimitado las categorías de ciudades mayores (como cabeceras de las MAU) y ciudades medias (como cabeceras de las MAU). Esto ha permitido diferenciar las dinámicas de crecimiento y las expectativas de crecimiento urbanísticas no solo entre categorías de áreas urbanas (GAU vs MAU), sino también entre lo ocurrido en los municipios "centrales" (municipio mayor de cada área) respecto al resto de los municipios que componen las áreas urbanas. Esta diferenciación ha resultado particularmente interesante ya que, como se detalla más adelante, se aprecian dinámicas evolutivas diferenciales en las periferias de las áreas, fuera de los municipios principales, en los que se ha puesto de manifiesto más claramente el referido proceso de dispersión urbana. Finalmente, hay que indicar también que el análisis estadístico efectuado se ha completado con una categoría adicional, la de las áreas urbanas pequeñas (ciudades de entre 10.000 y 50.000 habitantes) para poder contextualizar la dinámica urbana general del conjunto de elementos del sistema.

3 El Atlas incluye datos sobre 86 áreas urbanas mayores de 50.000 habitantes que agrupan un total de 753 municipios. Estos municipios representan apenas el 9\% del total nacional y en términos de superficie ocupan menos de un 10\%, si bien en ellos habitan más de 32 millones de habitantes según los datos del Padrón Municipal de 2018 — cerca del 70\% del total de la población-. La delimitación de las áreas urbanas que se establece en el Atlas parte de unos criterios que podemos resumir en los siguientes: las áreas urbanas deben contar con un municipio de al menos 50.000 habitantes; los municipios a incluir en las áreas plurimunicipales tendrán como mínimo 1.000 habitantes; se añaden Soria y Teruel, por su condición de capitales provinciales, aunque cuentan con menor número de habitantes.

4 Siguiendo el criterio de la delimitación del propio Atlas, se han incluido también en el estudio como ciudades medias, y por lo tanto también como MAU, Soria y Teruel que, aunque cuentan con menor población, son consideradas en este grupo de ciudades por su condición de capital provincial. 
Figura 1. Distribución y localización de las grandes áreas urbanas (GAU) y de las áreas urbanas articuladas por ciudades medias (MAU)

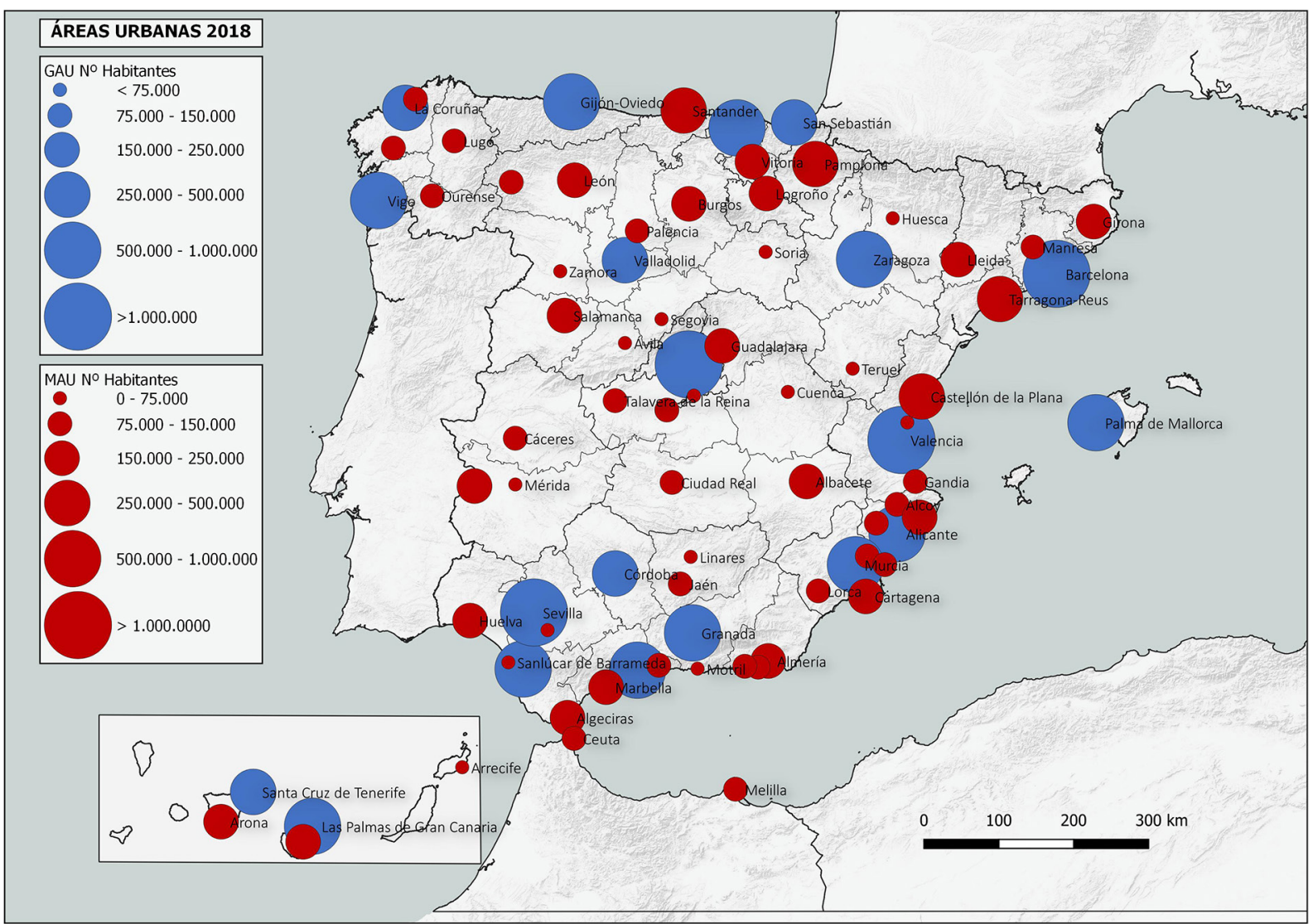

Fuente: Atlas Estadístico de las Áreas Urbanas del Ministerio de Transportes, Movilidad y Agenda Urbana (MTMA). 2018. Elaboración propia

El periodo de análisis se ha focalizado en las últimas cuatro décadas, con el interés de estudiar la evolución del sistema urbano en el marco del urbanismo municipalista desde el comienzo de la etapa democrática. Esto ha permitido identificar asimismo la evolución de las dinámicas urbanizadoras en los tres grandes periodos del urbanismo español reciente: 1979-1991 —reordenación-comienzo del crecimiento—, 1992-2007 —expansión acelerada-"boom" inmobiliario- y 2008-2019 —crisis económica-estancamiento- (Bellet, 2020). Sobre esta distribución temporal, se han establecido series decenales de información (1981, 1991, 2001, 2011 y 2018) referidas a las citadas variables (población, vivienda y suelo urbanizado).

Para el estudio de las dinámicas de crecimiento se ha manejado la información procedente de los Censos de Población, Edificios y Viviendas de 1981, 1991, 2001 y 2011, completando la serie con los datos obtenidos del Padrón Municipal de Habitantes para el año 2018. El análisis sobre la evolución del parque de viviendas se ha desarrollado igualmente con la información obtenida del INE, mediante la consulta de los datos de los Censos de Vivienda entre 1981 y 2011. En el caso de esta variable, el dato relativo al número de viviendas en 2018 se ha completado mediante una estimación a nivel municipal del parque inmobiliario, obtenida a partir de los datos de referencia provincial que proporciona el MTMA, considerando la ratio de crecimiento 2011-2018. En tercer lugar, la fuente de información manejada para el estudio de la evolución del suelo artificializado ha sido obtenida del proyecto Corine Land Cover ${ }^{5}$. Esta fuente presenta sus resultados en capas de información geográfica, por lo que se han analizado estos archivos en un

5 Los datos sobre suelo artificializado proceden del proyecto europeo Corine Land Cover (Coordination of Information on the Environment-CLC). El proyecto, que dirige la Agencia Europea de Medio Ambiente (AEMA), tiene como objetivo fundamental la captura de datos de tipo numérico y geográfico para la creación de una base de datos europea a escala 1:100.000 sobre la cobertura y uso del territorio mediante la fotointerpretación a través de imágenes recogidas por la serie de satélites LandSat y SPOT. 
Sistema de Información Geográfica (QGIS) para realizar el filtrado de las diferentes categorías de suelo y obtener la información ordenada y tabulada para las series temporales del mismo periodo. En este caso se ha trabajado así con información sobre el suelo artificializado en los años 1987, 2000, 2005, 2011 y 2018 , según las fechas de cada serie cartográfica del referido proyecto. Finalmente, para poder estudiar las expectativas de crecimiento en suelo y vivienda se ha manejado la información que sobre planeamiento municipal vigente ofrece el Sistema de Información Urbana (SIU) del Ministerio de Transportes, Movilidad y Agenda Urbana en su última versión (MTMA, 2018b). En este caso, se ha tabulado la información relativa a los potenciales de desarrollo de suelo (superficies en áreas de desarrollo), edificabilidad prevista y potenciales de vivienda de los diferentes municipios y áreas urbanas establecidas (GAU y MAU). La información proporcionada por todas estas fuentes se ha tratado después estadísticamente, elaborando tablas y cuadros resumen de las dinámicas más importantes por categorías. Asimismo, estos datos se han vinculado al referido SIG, para obtener cartografía temática que permitiera sintetizar los resultados obtenidos.

\section{Resultados}

\subsection{La huella del urbanismo expansivo en áreas urbanas intermedias (1981-2018): crecimiento moderado, "boom" inmobiliario y nuevo cambio de ciclo}

Desde la mitad de los años ochenta, las áreas urbanas articuladas por ciudades medias en España iniciaron una fase de crecimiento moderado vinculado a los nuevos planes generales que se habían ido gestando desde el comienzo del periodo democrático. El urbanismo desplegado durante los primeros años de los ayuntamientos democráticos se centró básicamente en la reforma y mejora de las estructuras y formas heredadas, tratando de mejorar los estándares de equipamiento y servicios urbanos, en general, transformar las periferias desestructuradas e impulsar o recuperar los centros urbanos en declive o fuerte proceso de transformación (Ferrer y Solà-Morales, 2005). El contexto a finales de esos años va cambiando con la integración del país a las dinámicas europeas y el traspaso de competencias a las diferentes comunidades autónomas que resultará en un reposicionamiento de las ciudades medias en el conjunto urbano del país que experimentaran notables crecimientos y mayores expectativas (Bellet y Olazabal, 2017)

Desde el inicio de los años noventa estas ciudades comenzaron a extenderse y los nuevos crecimientos afectaron de forma ya intensa a los municipios colindantes generando aglomeraciones supramunicipales y áreas urbanas entorno a ellas. Se iniciaron claramente procesos de extensión de la trama urbanizada, intensificándose las dinámicas de crecimiento. Este proceso dio lugar a nuevos espacios urbanos acompañados de profundas transformaciones morfológicas, funcionales y sociales de las ciudades. Estas nuevas piezas de la ciudad más allá de los límites municipales de las ciudades originales generaron una nueva estructura dispersa que comenzó a modificar claramente los rasgos de la tradicional forma y estructura urbana (compacta, intensa y con cierta densidad) (Cebrián, 2013; Bellet y Olazabal, 2017).

Iniciado este proceso de dispersión urbana, el verdadero crecimiento y expansión más importante de estas ciudades se produjo durante la década del 2000, al ritmo de los masivos desarrollos de suelos urbanizables y la producción de vivienda en el marco del "boom" inmobiliario: 1997-2007. Como ya se ha estudiado, este proceso fue configurando alrededor de las primitivas ciudades medias un conjunto urbano más extenso y menos denso, formando ciudades supramunicipales por la suma de fragmentos sin continuidad en su tejido urbano (Zúñiga, 2016; Olazábal y Bellet, 2018). Se han producido de este modo cambios muy significativos en el paisaje, la forma y la estructura urbana mediante procesos de consumo intensivo de suelo y extensivos en urbanización, con el resultado de una clara fragmentación en las formas de producción de los nuevos espacios urbanos (y la transformación de los existentes) (Cebrián y Sánchez, 2019).

Estos recientes procesos de urbanización pueden caracterizarse así de intensivos, por el volumen de la producción de suelo y vivienda; extensivos, por su alcance territorial; selectivos y fragmentados, por la fuerte especialización de los usos del suelo; y de carácter netamente privativo, por las morfologías de enclave y auto encerramiento que adoptan muchos de los diferentes desarrollos inmobiliarios. Asimismo, provocaron una significativa fragmentación espacial y social, modificando el rol y la dinámica territorial de estas ciudades (Bellet y Olazabal, 2017; Martínez, et al., 2020). E, incluso, estas resultaron en la mayor especialización funcional de algunas áreas urbanas ya que la extensión del fenómeno urbanizador va más allá de lo meramente residencial y una parte muy relevante de la expansión responde al importante desarrollo de suelo destinado a usos industriales, logísticos u otras actividades económicas durante el "boom" inmobiliario (Andrés, 2019 y 2020). 
Tabla 1. Dinámicas de crecimiento en municipios y áreas urbanas. 1981-2018

\begin{tabular}{|c|c|c|c|c|c|}
\hline & \multirow[b]{2}{*}{ Municipios } & \multirow[b]{2}{*}{ Superficie km² } & \multicolumn{3}{|c|}{$\begin{array}{l}\text { Dinámicas de crecimiento } \\
\text { (\% anual) }\end{array}$} \\
\hline & & & $\begin{array}{l}\text { Población } \\
\text { (1981-2018) }\end{array}$ & $\begin{array}{c}\text { Vivienda } \\
(1981-2018)\end{array}$ & $\begin{array}{l}\text { Suelo Artific. } \\
\text { (1987-2018) }\end{array}$ \\
\hline GAU & 488 & 23.045 & 0,74 & 1,84 & 2,00 \\
\hline Ciudades mayores & 24 & 7.602 & 0,15 & 1,29 & 1,61 \\
\hline MAU & 245 & 24.172 & 1,31 & 2,91 & 2,80 \\
\hline Ciudades medias & 66 & 17.376 & 0,96 & 2,53 & 2,38 \\
\hline $10.000-50.000$ & 363 & 58.877 & 1,01 & 2,57 & 2,67 \\
\hline Total Urbano o AU & 1.096 & 106.094 & 0,89 & 2,19 & 2,35 \\
\hline
\end{tabular}

\begin{tabular}{|c|c|c|c|c|c|c|c|}
\hline & & & & \multicolumn{4}{|c|}{$\begin{array}{l}\text { Dinámicas de crecimiento } \\
\text { (\% anual) - POBLACIÓN }\end{array}$} \\
\hline & $\begin{array}{c}\text { Población } \\
1981\end{array}$ & $\begin{array}{l}\text { Población } \\
2018\end{array}$ & $\begin{array}{c}\text { Índice } \\
\text { Crecimiento } \\
(1981=100)\end{array}$ & \% 1981-1991 & $\% 1991-2001$ & $\% 2001-2011$ & $\%$ 2011-2018 \\
\hline GAU & 18.623 .327 & 23.704 .235 & 127,28 & 0,41 & 0,6 & 1,39 & 0,17 \\
\hline Ciudades mayores & 11.920 .928 & 12.574 .674 & 105,48 & $-0,14$ & $-0,08$ & 0,78 & 0,00 \\
\hline MAU & 5.458 .167 & 8.110 .564 & 148,60 & 1,07 & 1,02 & 2,11 & 0,08 \\
\hline Ciudades medias & 4.677 .881 & 6.337 .802 & 135,48 & 0,95 & 0,69 & 1,60 & $-0,03$ \\
\hline $10.000-50.000$ & 5.021 .386 & 6.895 .857 & 137,33 & 0,59 & 0,87 & 1,96 & $-0,04$ \\
\hline Total Urbano o AU & 29.102 .880 & 38.710 .656 & 133,01 & 0,57 & 0,73 & 1,64 & 0,11 \\
\hline
\end{tabular}

\begin{tabular}{|c|c|c|c|c|c|c|c|}
\hline & & & & \multicolumn{4}{|c|}{$\begin{array}{l}\text { Dinámicas de crecimiento } \\
\text { (\% anual) - VIVIENDA }\end{array}$} \\
\hline & $\begin{array}{c}\text { Vivienda } \\
1981\end{array}$ & $\begin{array}{l}\text { Vivienda } \\
2018\end{array}$ & $\begin{array}{c}\text { Índice } \\
\text { Crecimiento } \\
(1981=100)\end{array}$ & \% 1981-1991 & $\%$ 1991-2001 & $\% 2001-2011$ & $\%$ 2011-2018 \\
\hline GAU & 6.746 .453 & 11.345 .204 & 168,17 & 1,36 & 2,22 & 1,87 & 0,28 \\
\hline Ciudades mayores & 4.255 .467 & 6.287 .373 & 147,75 & 0,89 & 1,67 & 1,4 & 0,28 \\
\hline MAU & 2.164 .305 & 4.492 .842 & 207,59 & 2,46 & 3,13 & 2,48 & 0,24 \\
\hline Ciudades medias & 1.795 .890 & 3.479 .172 & 193,73 & 2,16 & 2,89 & 2,14 & 0,25 \\
\hline $10.000-50.000$ & 2.085 .076 & 4.065 .738 & 194,99 & 2,49 & 2,51 & 2,28 & 0,23 \\
\hline Total Urbano o AU & 10.995 .834 & 19.903 .784 & 181,01 & 1,79 & 2,47 & 2,09 & 0,26 \\
\hline
\end{tabular}

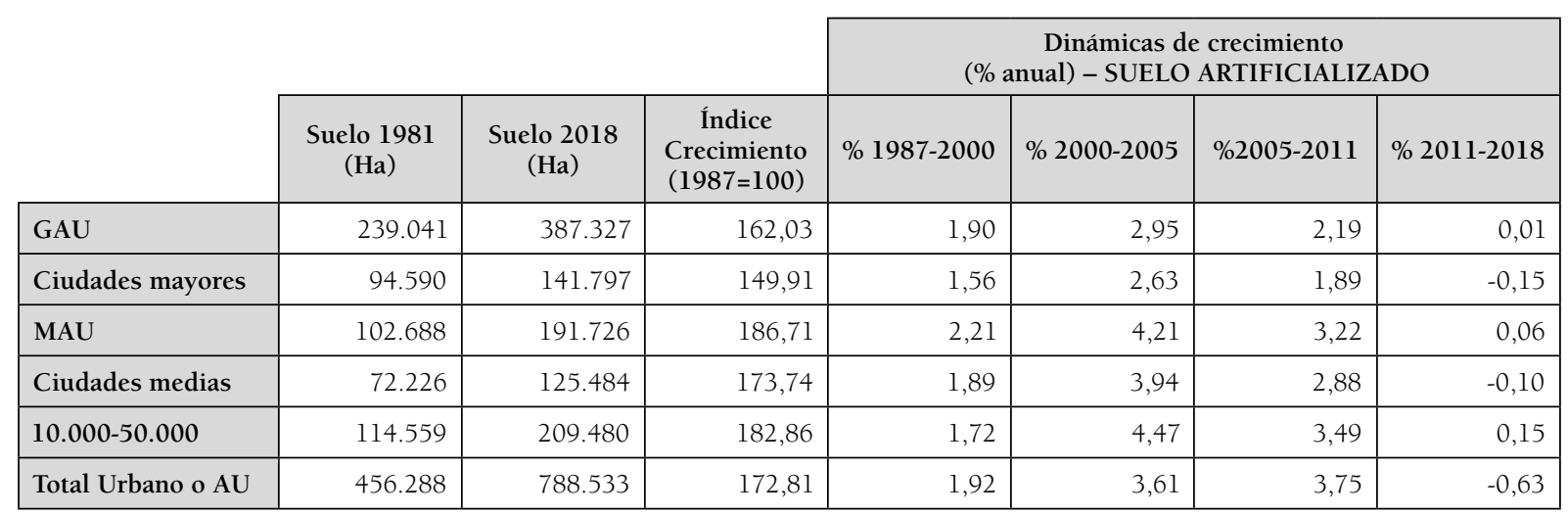

Fuente: Censos de Población y Viviendas de 1981, 1991, 2001 y 2011; Padrón Municipal de Habitantes 2018; Estadística de Viviendas 2018 del MTMA (estimación a partir del dato provincial según ratios de crecimiento 2011-2018); Corine Land Cover (CLC) (1987, 2000, 2005, 2011 y 2018). Elaboración propia 
Como consecuencia de esta sucesión de transformaciones, la extensión de las áreas urbanas intermedias en las últimas cuatro décadas ha sido muy notable, hasta el punto de que se ha modificado el argumento tradicional de que dichas ciudades están esencialmente configuradas por un núcleo histórico central que se expandió básicamente en el crecimiento del desarrollismo industrial (durante las décadas de 1960 y 1970). Actualmente, cerca de la mitad del suelo urbanizado en las ciudades medias españolas es posterior a 1980, lo que pone de manifiesto la significativa transformación urbanística de estas ciudades en las décadas del periodo analizado. Si se desgrana con detenimiento la información que contiene la tabla 1, en la que se incluye la evolución de tres de las variables de estudio (población, vivienda y suelo urbanizado) entre 1981 y 2018, se puede confirmar la intensidad de este proceso.

En concreto, las áreas urbanas intermedias han pasado de apenas 100.000 ha de suelo urbanizado en 1981 a más de 191.000 ha en 2018, esto es un incremento del 86\% del espacio urbano en las últimas cuatro décadas. En el mismo periodo, el número de viviendas en estas ciudades ha pasado de 2,1 a 4,5 millones de inmuebles, manifestando un crecimiento aún más intenso (del 107\% del parque). Sin embargo, la población únicamente ha variado de 5,4 a 8,1 millones de personas, con un índice de crecimiento del $48 \%$. Los datos generales son, por lo tanto, bien reveladores ya que, de partida, se observa cómo el proceso de urbanización manifiesta un fuerte desajuste entre el crecimiento demográfico y la expansión urbanística e inmobiliaria, indicando las pautas de un modelo altamente especulativo y que, como ya se ha mostrado en otros estudios, tiende a la baja densidad (Monclús, 1998). Pero más allá de esta premisa, los cambios en la intensidad del proceso y el carácter de la nueva urbanización sugieren una serie de cuestiones que muestran singularidades en las formas del crecimiento urbano acumulado en las áreas urbanas intermedias:

- En primer lugar, se puede observar cómo las MAU experimentan en los últimos 40 años un crecimiento relativo significativamente superior al de la media de las ciudades españolas. Las áreas urbanas intermedias incrementan su población en casi un 50\% de efectivos respecto a los años ochenta y multiplican por dos el volumen de su parque inmobiliario y la superficie de su espacio urbanizado situándose a la cabeza del sistema urbano y muy por encima de las GAU. En concreto, el incremento demográfico de estas áreas en este periodo está 15 puntos porcentuales por encima de la media del resto de elementos del sistema urbano y 21 puntos más que el de las grandes ciudades, presentando tendencias de crecimiento aún más acusadas en los casos de la vivienda (26 puntos porcentuales sobre la media y 39 sobre las grandes ciudades) y el suelo urbanizado ( 14 puntos porcentuales sobre la media y 24 sobre las grandes ciudades). Si se observa el porcentaje de variación anual del crecimiento, las diferencias son igualmente notables ya que las áreas urbanas intermedias manifiestan una variación positiva de $1,31 \%$ anual en la dinámica demográfica, un 2,91\% anual en el crecimiento de la vivienda y un 2,80\% anual en la expansión del suelo urbanizado. Los mismos valores son notablemente inferiores en el caso de las grandes áreas urbanas - $0,74 \%$ anual en población, 1,84\% anual en vivienda y $2 \%$ anual en suelo urbanizado- y en el conjunto del sistema urbano nacional $-0,89 \%$ anual en población, 2,19\% anual en vivienda y 2,35\% anual en suelo urbanizado- Por lo tanto, puede decirse que, en términos relativos, las áreas urbanas intermedias son claramente la tipología de ciudad que más crece durante las últimas décadas en España.

- La segunda cuestión relevante viene determinada por esa intensa diferencia que se observa entre el crecimiento de la población, por un lado, y el parque de viviendas y el suelo urbanizado, por otro. Tal y como se ha visto, como norma general, el crecimiento inmobiliario y la expansión urbana doblan la ratio del incremento demográfico en las áreas urbanas intermedias, confirmándose el planteamiento realizado acerca del carácter especulativo del crecimiento basado en un tipo de urbanismo que se acoge a los principios de la liberalización del suelo y de un crecimiento económico basado en el consumo de suelo urbano y la producción inmobiliaria. Y esta cuestión se acentúa más en términos comparativos, ya que nuevamente las MAU destacan respecto a la media y el resto de elementos del sistema urbano. Quiere esto decir, que estas áreas urbanas no solo crecen más que el resto en términos relativos, sino que en ellas se manifiesta además el desajuste más intenso entre el crecimiento demográfico y la expansión urbana ${ }^{6}$. Puede decirse, por tanto, que son las MAU el tipo de ciudad en el que mejor se aprecia, si cabe, la consolidación de un modelo de urbanización con menor densidad y tendente a la difusión mediante pautas de fragmentación.

\footnotetext{
6 En este proceso hay que destacar la singularidad de la intensidad del crecimiento demográfico que se produce en las MAU durante la década del 2.000 , con una tasa que dobla a la del resto de ciudades del sistema urbano. Pese a que, en conjunto, tal y como se ha indicado, el crecimiento demográfico está muy desacompasado de la expansión urbana e inmobiliaria.
} 
Figura 2. Índices de crecimiento en municipios y áreas urbanas. 1981-2018. 1981=100

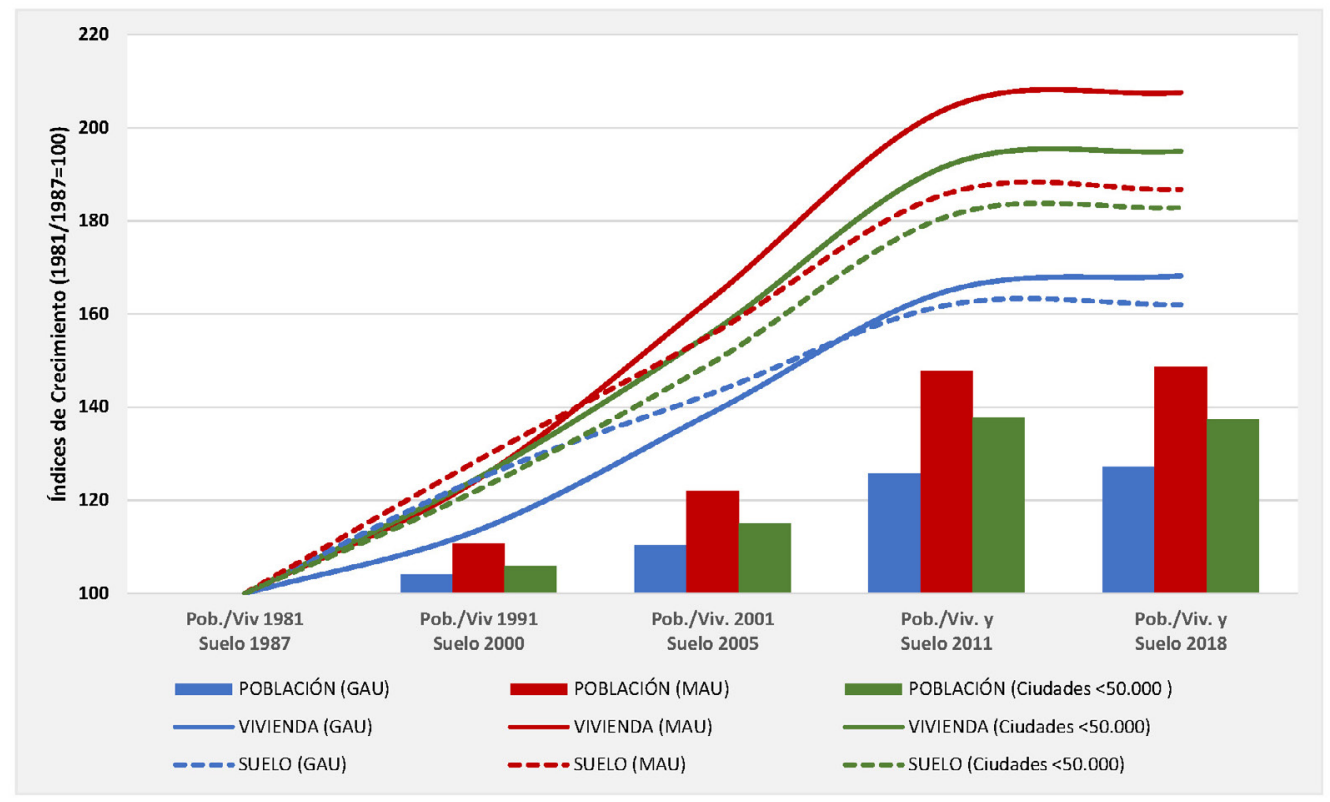

Fuente: Censos de Población y Viviendas de 1981, 1991, 2001 y 2011. Padrón Municipal de Habitantes 2018. Estadística de Viviendas 2018 del MTMA (estimación a partir del dato provincial según ratios de crecimiento 2011-2018). Corine Land Cover (CLC) (1987, 2000, 2005, 2011 y 2018). Elaboración propia

- En tercer lugar, debe destacarse, tal y como puede apreciarse en los gráficos que se adjuntan, la intensidad creciente de este proceso durante las últimas cuatro décadas, pudiendo diferenciarse claramente las fases del crecimiento moderado inicial, la expansión acelerada del "boom" inmobiliario, en un segundo momento, y una clara ralentización del proceso durante los últimos años. Tal y como reflejan las citadas figuras y se puede ver en la mencionada tabla, desde la década de 1980 se inicia un crecimiento sostenido que se acelera notablemente en las décadas de 1990 y 2000. De nuevo las áreas urbanas articuladas por ciudades medias manifiestan las ratios más altas del sistema urbano, con porcentajes de incremento anual de la vivienda y el suelo por encima del 3,1 y el 4,2\% durante esta fase central del crecimiento - frente a un 2,2 y 2,9 de las GAU-.

- Finalmente, como cuestión también ilustrativa del proceso de expansión hacia la periferia, cabe destacar que son los municipios menores de las diferentes aglomeraciones o áreas urbanas los que experimentan de forma relativa los mayores crecimientos en las diferentes variables - frente al menor dinamismo de los municipios de las ciudades centrales-. Sólo hace falta contrastar los crecimientos del conjunto de las GAU con los de las ciudades mayores, o los crecimientos del conjunto de las MAU con el experimentado en las ciudades medias para advertir esta cuestión. En el caso de las GAU, los municipios del entorno crecen un $22 \%$ más en población, un $21 \%$ más en vivienda y un 13\% más en suelo urbanizado que la ciudad central durante el periodo 1981-2018. En el caso de las MAU, las periferias superan a las ciudades medias centrales en un 13\% — población-, 14\% —vivienda-y $13 \%$ — suelo urbanizado-.

El comportamiento de todas las variables indica así la evolución del proceso de expansión y crecimiento que han sufrido las ciudades españolas en las últimas décadas y, muy especialmente, la intensidad con la que se manifiesta este fenómeno en las áreas urbanas que articulan las ciudades medias. En esta tipología de ciudades se ha consolidado una estructura urbana con un significativo grado de dispersión que no existía al comienzo de este periodo y se manifiestan unos índices relativos de vivienda y suelo urbanizado por cada 1.000 habitantes notablemente más altos que los del resto de ámbitos urbanos (entre un 15 y un 50\% superiores a los de las grandes ciudades). Como media, en las MAU hay 553 viviendas/1.000 hab frente a las 478 viviendas/1.000 hab de las GAU y la diferencia es similar en el caso de la ratio de suelo urbanizado por cada 1.000 personas ( 23 frente a $16 \mathrm{ha}$ ). Sin embargo, estas trasformaciones no son homogéneas y varían en función de la posición geográfica de las áreas urbanas, su articulación a los sistemas territoriales más dinámicos y la incidencia y las características de las políticas aplicadas a escala local. 
Figura 3. Porcentajes de variación anual por periodos en municipios y áreas urbanas. 1981-2018

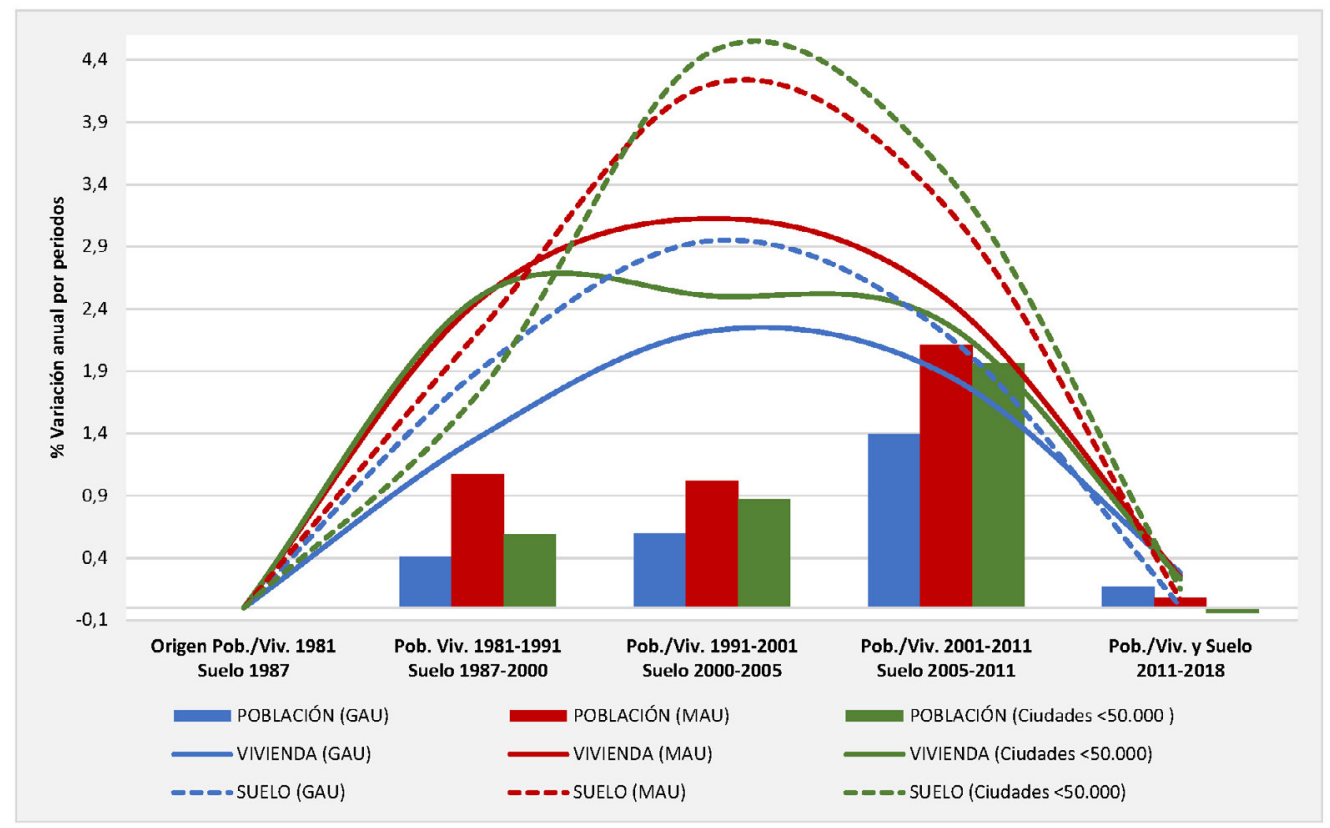

Fuente: Censos de Población y Viviendas de 1981, 1991, 2001 y 2011. Padrón Municipal de Habitantes 2018. Estadística de Viviendas 2018 del MTMA (estimación a partir del dato provincial según ratios de crecimiento 2011-2018). Corine Land Cover (CLC) (1987, 2000, 2005, 2011 y 2018). Elaboración propia

Figura 4. Dinámica de crecimiento de la población en las áreas urbanas españolas (GAU-MAU; \% variación anual 1981-2018)

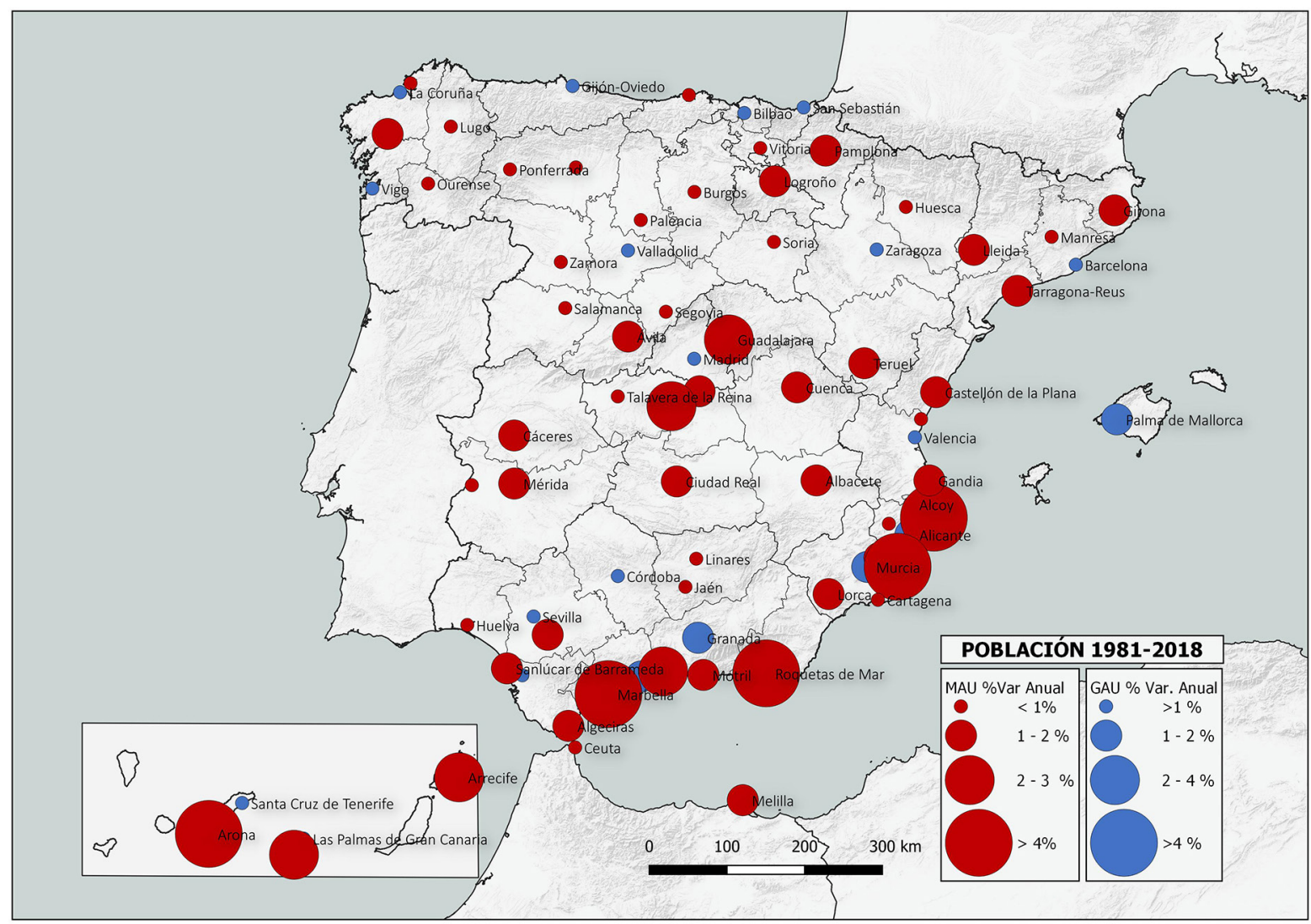

Fuente: Censos de Población y Viviendas de 1981, 1991, 2001 y 2011. Padrón Municipal de Habitantes 2018. Elaboración propia 
Figura 5. Dinámica de crecimiento de la vivienda en las áreas urbanas españolas (GAU-MAU; \% variación anual 1981-2018)

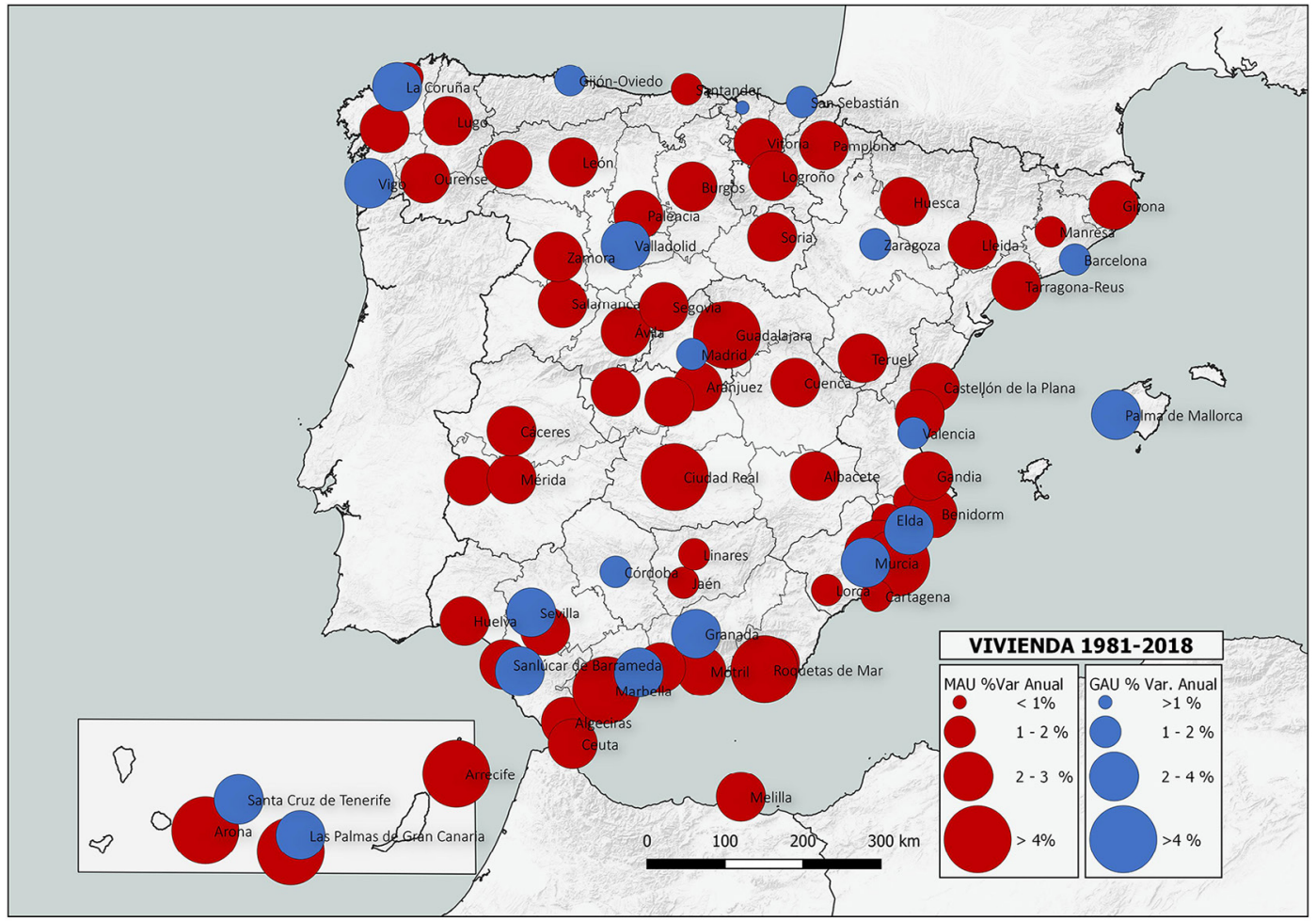

Fuente: Censos de Población y Viviendas de 1981, 1991, 2001 y 2011. Estadística de Viviendas 2018 del MTMA (estimación a partir del dato provincial según ratios de crecimiento 2011-2018). Elaboración propia

Figura 6. Dinámicas de crecimiento del suelo urbanizado en las áreas urbanas españolas (GAU-MAU; \% variación anual 1981-2018)

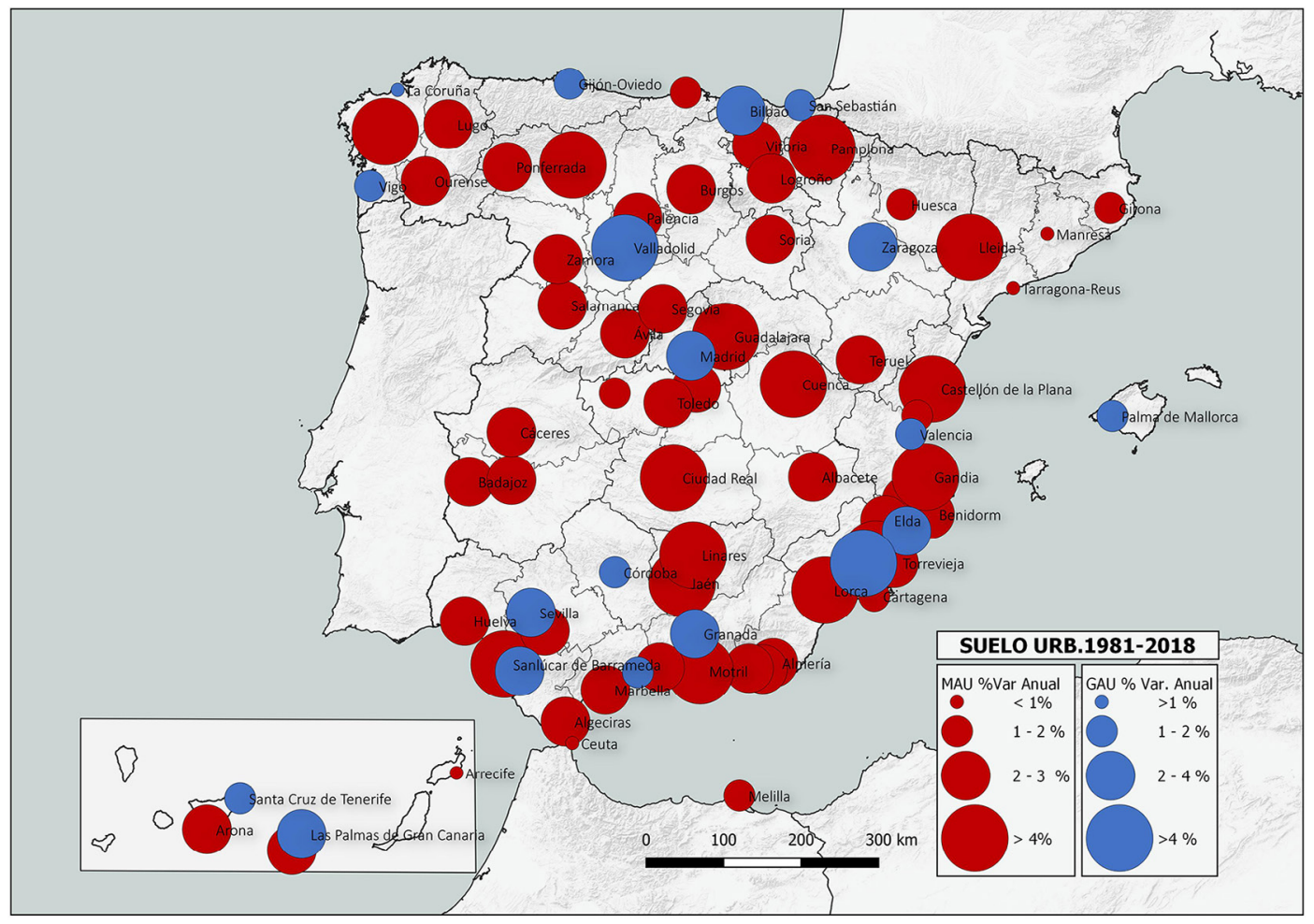

Fuente: Corine Land Cover (CLC) (1987, 2000, 2005, 2011 y 2018). Elaboración propia 
Figura 7. Gradiente comparativo del crecimiento entre población y vivienda-suelo en las áreas urbanas españolas (GAU-MAU; \% variación anual 1981-2018)

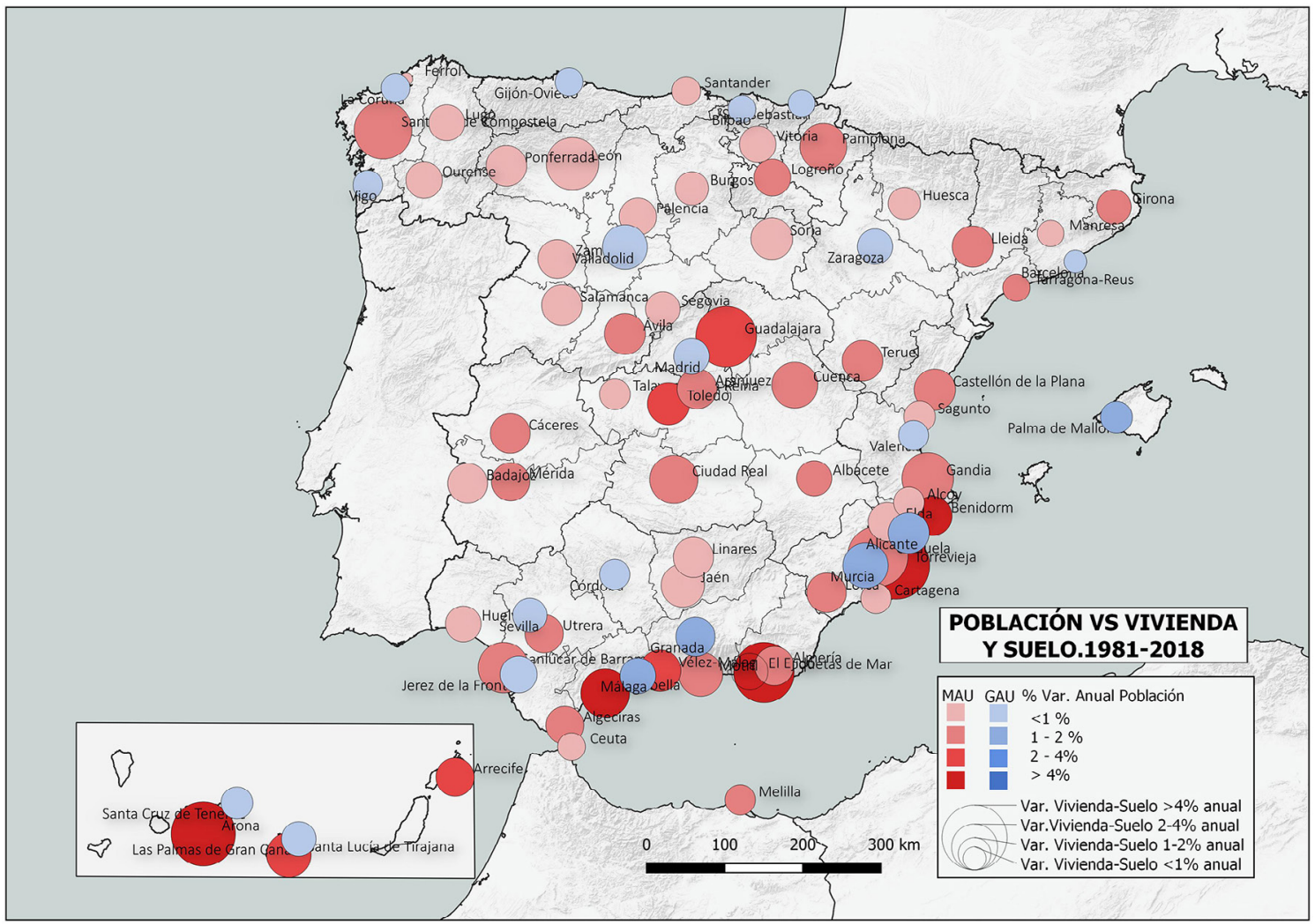

Fuente: Censos de Población y Viviendas de 1981, 1991, 2001 y 2011. Padrón Municipal de Habitantes 2018. Estadística de Viviendas 2018 del MTMA (estimación a partir del dato provincial según ratios de crecimiento 2011-2018). Corine Land Cover (CLC) (1987, 2000, 2005, 2011 y 2018). Elaboración propia

En las Figuras 4 a 7 puede verse la distribución territorial de estas dinámicas de crecimiento, mediante la representación cartográfica de las variables de población, vivienda y suelo y su comparación evolutiva. Los mapas confirman claramente el resultado obtenido en el análisis de los datos, en cuanto a la diferencia relativa de crecimiento ya explicada que se aprecia en las áreas urbanas intermedias. Como puede verse, las MAU crecen muy por encima de las GAU y se observan igualmente los desajustes entre crecimiento demográfico y expansión urbana. En este sentido, se diferencian claramente las ciudades medias del litoral mediterráneo, vinculadas a las dinámicas turísticas, en las que sí se aprecia la intensidad demográfica a la par del crecimiento urbano. Más allá de esta cuestión, como norma general, la cartografía muestra de forma evidente la consolidación de los sistemas dinámicos de áreas urbanas articuladas por ciudades medias: por un lado, el conjunto de ciudades que, desde Algeciras a Girona, configuran el eje mediterráneo - con una especial intensidad del proceso urbanizador en Alicante, Valencia y Murcia-; las ciudades medias vinculadas a la dinámica metropolitana de Madrid, con el área urbana de Guadalajara como máximo exponente de la expansión; en tercer lugar, las ciudades vinculadas a la expansión de la conurbación de Bilbao y el crecimiento de las ciudades vascas (Vitoria, Logroño, Pamplona), con dinámicas expansivas llamativamente por encima de su transformación demográfica; el conjunto de ciudades de la costa gallega (Vigo-Santiago-Coruña); y la mayor parte de ciudades medias del interior peninsular, con una generalizada atonía demográfica y en las que, sin embargo, se presenta igualmente intenso el proceso expansivo del "boom" inmobiliario. Sin duda alguna, estos mapas muestran claramente la huella del urbanismo expansivo sostenido en las áreas urbanas españolas en el periodo 1981-2018 y dibujan claramente el resultado del fuerte crecimiento y la gran extensión en suelo urbanizado e inmobiliaria de todas las ciudades durante este periodo. Pero si, más allá de la tendencia general y de las distintas fases y particularidades comentadas, se observa el último periodo, es posible atisbar claramente un cambio de ciclo. Resulta, en consecuencia, obligado estudiar si el modelo urbano y de crecimiento del planeamiento urbanístico refleja estas nuevas circunstancias. 


\section{2. ¿Cambio de modelo? Modelos de ciudad y expectativas de crecimiento en el planeamiento municipal vigente de las áreas urbanas articuladas por ciudades medias}

En esta aportación, a falta de un estudio de las diferentes situaciones en detalle, lo que se pretende analizar son los datos generales sobre estructura de la clasificación de suelo y las previsiones de crecimiento presentes en el mismo (áreas de desarrollo en suelo urbano no consolidado y suelo urbanizado delimitado; viviendas previstas) al objeto de comprobar si esta hipótesis sobre la falta de encaje entre las ideas del planeamiento urbano y sus evidencias se corrobora. Para ello, como ya se ha explicado, se ha utilizado una cuarta variable en la investigación, sumando a los datos de población, vivienda y suelo ya estudiados, la consideración de la información sobre expectativas de crecimiento del planeamiento vigente. Los datos han sido igualmente tratados como en el apartado anterior por áreas urbanas y se ha analizado también la información en las distintas escalas propuestas, desde las ciudades más pequeñas a las GAU, considerando la escala intermedia de las MAU.

Tabla 2. Áreas de desarrollo, expectativas e indicadores de crecimiento según el planeamiento vigente en áreas y municipios urbanos de más de 10.000 habitantes en España. Año 2018

\begin{tabular}{|l|c|c|c|c|r|}
\cline { 2 - 6 } \multicolumn{1}{c|}{} & $\begin{array}{c}\text { Áreas de } \\
\text { desarrollo } \mathbf{( H a})\end{array}$ & $\begin{array}{c}\text { Áreas de desarrollo/ } \\
\text { Suelo Urbano }\end{array}$ & $\begin{array}{c}\text { Edificabilidad en } \\
\text { áreas de desarrollo } \\
\left(\mathbf{m}^{2}\right)\end{array}$ & $\begin{array}{c}\text { \% Edificabilidad en } \\
\text { uso residencial }\end{array}$ & $\begin{array}{c}\text { Viviendas } \\
\text { previstas }\end{array}$ \\
\hline GAU & 140.151 & 0,55 & 551.760 .958 & 62,4 & 2.708 .610 \\
\hline Ciudades mayores & 44.039 & 0,49 & 188.653 .306 & 67,2 & 1.065 .658 \\
\hline MAU & 102.725 & 0,85 & 391.806 .883 & 68,2 & 2.028 .066 \\
\hline Ciudades medias & 63.745 & 0,80 & 182.052 .966 & 72,7 & 1.401 .811 \\
\hline 10.000-50.000 & 109.071 & 0,80 & 450.216 .509 & 56,5 & 1.861 .242 \\
\hline Total Urbano o AU & 351.948 & 0,68 & 1.393 .784 .350 & 62,1 & 6.597 .918 \\
\hline
\end{tabular}

Fuente: Atlas Estadístico de las Áreas Urbanas del MTMA. 2018. Elaboración propia

Lejos de lo que parecería desprenderse de los actuales discursos sobre la moderación en los crecimientos, que llegan incluso de facto a la reclasificación de suelo urbanizable a suelo no urbanizable realizada en algunas comunidades (Calderón y García, 2017), la expectativa de desarrollo de suelo en el planeamiento urbano en muchos municipios españoles continúa siendo considerablemente alta. Según los datos de información urbanística del Atlas Estadístico Digital de las Áreas Urbanas del MTMA a fecha de 2018 los municipios urbanos (más de 10.000 habitantes) o contenidos en áreas urbanas (delimitadas en Atlas Estadístico) tienen un potencial de crecimiento de algo más de 350.000 ha (460.000 Ha en todos los municipios españoles contemplados en el Atlas). Esta capacidad de nuevos sectores residenciales de desarrollo se corresponde con un volumen potencial de 6.597.918 viviendas, cuando el MTMA calcula que el parque de viviendas en el conjunto del Estado en 2018 es de 25.712.744 inmuebles. Es decir, el planeamiento urbano actualmente vigente en las ciudades españolas permitiría un crecimiento del parque, en el contexto actual de paralización y crisis, superior al 25\% del parque ya existente en la actualidad. Se trata de unas perspectivas de crecimiento muy notables que no solo contradicen los discursos oficiales sobre la sostenibilidad del modelo, sino que además no encajan con la evidencia de la dinámica urbanizadora que reflejan los datos desde el año 2008 y las perspectivas del mismo a medio plazo. Estas altas expectativas de crecimiento encuentran un primer motivo en el hecho que el 58,4\% del planeamiento vigente fue redactado entre 1992 y 2007, un período en el que las dinámicas de crecimiento demográficas eran altas y fueron multiplicadas en materia de producción de suelo por un mercado claramente expansivo y especulativo, como se ha visto.

Este desajuste es particularmente intenso de nuevo en el caso de las áreas urbanas articuladas por ciudades medias, en las que la expectativa de crecimiento del planeamiento se mantiene con intensidad y refleja de nuevo una clara variación entre la realidad de lo ya urbano consolidado y la capacidad de crecimiento del plan (áreas de desarrollo: suelo urbano no consolidado + suelo urbanizable). Concretamente, las áreas urbanas intermedias albergan el 21\% de la población urbana y representan el 22,8\% de la superficie, pero alcanzan sin embargo el 29,2\% de la superficie en áreas de desarrollo, el 30,49\% de la edificabilidad prevista y el 30,7\% de las viviendas en sectores o áreas de desarrollo futuros (suelo urbanizable y urbano no consolidado) del conjunto de municipios y áreas urbanas del país. En estos municipios se prevé una capacidad de 2.028.066 nuevas viviendas en nuevos sectores con una superficie de 102.725 ha. 
De concretarse tales actuaciones, el parque de viviendas de las áreas urbanas articuladas por ciudades medias se incrementaría en un 49,5\% respecto al parque actual, incidiendo en fuerte transformación de estos conjuntos urbanos. Además, debe señalarse que buena parte de esas expectativas se concentran en los municipios del área urbana inmediatos a las ciudades medias dónde, de forma relativa, la producción inmobiliaria fue ya importante durante el anterior "boom" inmobiliario. Estos municipios concentran hoy buena parte de las reservas de suelo y potencial de vivienda de las áreas articuladas por ciudades medias.

Estas notables expectativas de crecimiento de las MAU pueden relacionarse, primero y como ya se ha indicado, con la fecha de aprobación de los Planes de Ordenación Urbana. De hecho, un 69\% de los Planes de Ordenación de los municipios de las MAU se aprobaron entre 1992 y 2008, el gran período de expansión urbana, lo que relaciona las previsiones de los actuales PGOU con el periodo del "boom". Aunque, por otra parte, también debe tenerse en cuenta que la localización de cada área, el perfil y la dinámica económica de cada territorio resultan otra clave explicativa de las diferencias existentes entre las expectativas de las áreas y los modelos de desarrollo urbano que estas reflejan.

En otros trabajos se ha mantenido que las ciudades medias, al menos las del interior peninsular, habían logrado mantenerse más o menos compactas hasta la explosión del "boom" inmobiliario, momento a partir del cual las manchas urbanas, además de dispersarse y fragmentarse por el territorio, se extendían con densidades menores (Olazabal y Bellet, 2019). En el apartado anterior se ha comprobado cómo, en efecto, las variables estadísticas tratadas corroboran este proceso y las dinámicas de urbanización de las últimas décadas ofrecen como resultado una estructura urbana intensamente alterada.

Lo que se plantea aquí es que el modelo urbano (cociente de suelo en áreas de desarrollo o suelo sectorizado sobre suelo urbano consolidado), tal y como se desprende del planeamiento municipal aprobado y vigente, parece apoyarse todavía en la expansión del crecimiento urbano basado además en la media y media-baja densidad. Dicho de otro modo, la propuesta de ciudad que contienen los PGOU vigentes actualmente en las MAU continúa siendo claramente expansiva y apuesta por la continuidad en la extensión de la urbanización. Y es que, la superficie ordenada en nuevos desarrollos en las áreas urbanas intermedias por el planeamiento actual implica que, en conjunto, podría aumentar el suelo urbano de estas ciudades en un 85\%. De hecho, estas ciudades incrementaron su superficie urbanizada entre 1981 y 2018 en aproximadamente 91.000 ha y el actual planeamiento prevé una cantidad de suelo aún mayor — más de 102.000 ha- para las expectativas de crecimiento vigentes.

En la Figura 8 se sintetizan las expectativas de crecimiento a través de un índice que relaciona el crecimiento de suelo en áreas de posible desarrollo con la densidad relativa del suelo urbano ya consolidado. Se destacan, con un círculo rojo, aquellas áreas urbanas cuyo planeamiento vigente permitiría duplicar ampliamente la superficie de suelo urbano consolidado si se desarrollaran el conjunto de las áreas previstas. Los municipios contenidos en estas áreas urbanas articuladas por ciudades medias presentan un índice de crecimiento superior al 1,25: Vélez-Málaga, Lorca, Toledo, Badajoz, Talavera, Cuenca, Ciudad Real, Costa del Sol, Guadalajara, Soria, Mérida, Palencia, Orihuela, El Ejido y Costa Blanca. En este grupo hay que señalar, además, que en muchos casos el modelo urbano existente, con mayor densidad vinculada a ciudades históricas, podría verse comprometida con el desarrollo de tal potencial de nuevo suelo.

El análisis más detallado de la superficie de estas áreas de desarrollo y el potencial de viviendas asociado a ellas permite caracterizar mejor las expectativas de crecimiento de las diferentes áreas urbanas. En la Figura 9 se ha representado la ratio entre superficie prevista en los nuevos desarrollos y su correspondencia con número de nuevas viviendas. El resultado es igualmente ilustrativo ya que en la mayor parte de áreas urbanas intermedias se aprecia una alta previsión de nuevo suelo urbanizable con una fuerte intensidad de nuevas viviendas. En el círculo señalado en color azul pueden identificarse las áreas urbanas de Costa del Sol, Costa Blanca, Toledo, Pamplona, León, Talavera de la Reina, Tarragona-Reus, Badajoz, Guadalajara, Lorca, Cartagena, Gran Canaria, Tenerife y Algeciras. Se trata de conjuntos en los que la previsión de nuevas viviendas es superior a las 40.000 viviendas en nuevos desarrollos con capacidad de más de 3.000 hectáreas de nuevos ámbitos —en algunos casos, como los de las áreas en litorales turísticos se alcanzan previsiones cercanas a 100.000 nuevas viviendas-. En un segundo grupo, destacado en color rojo, se pueden apreciar muchas de las capitales del interior peninsular, que igualmente mantienen un modelo de fuerte expectativa de crecimiento y modelizan el perfil tipo del planeamiento en este tipo de ciudades. Se trata de núcleos en cuya planificación está prevista una capacidad de nuevas áreas de desarrollo de entre 1.000 y 3.000 ha y con capacidad para construir un total de entre 20 y 50.000 viviendas - Jaén, Burgos, Mérida, Zamora, Palencia, Ciudad Real, Almería, Santiago de Compostela, Lugo, Salamanca, Castellón, Cáceres, Lleida, Vitoria, Santander, Logroño...-. 
Figura 8. El modelo urbano y el modelo de crecimiento: suelo en áreas de desarrollo y suelo urbano por habitante en áreas urbanas articuladas por ciudades medias (2018)

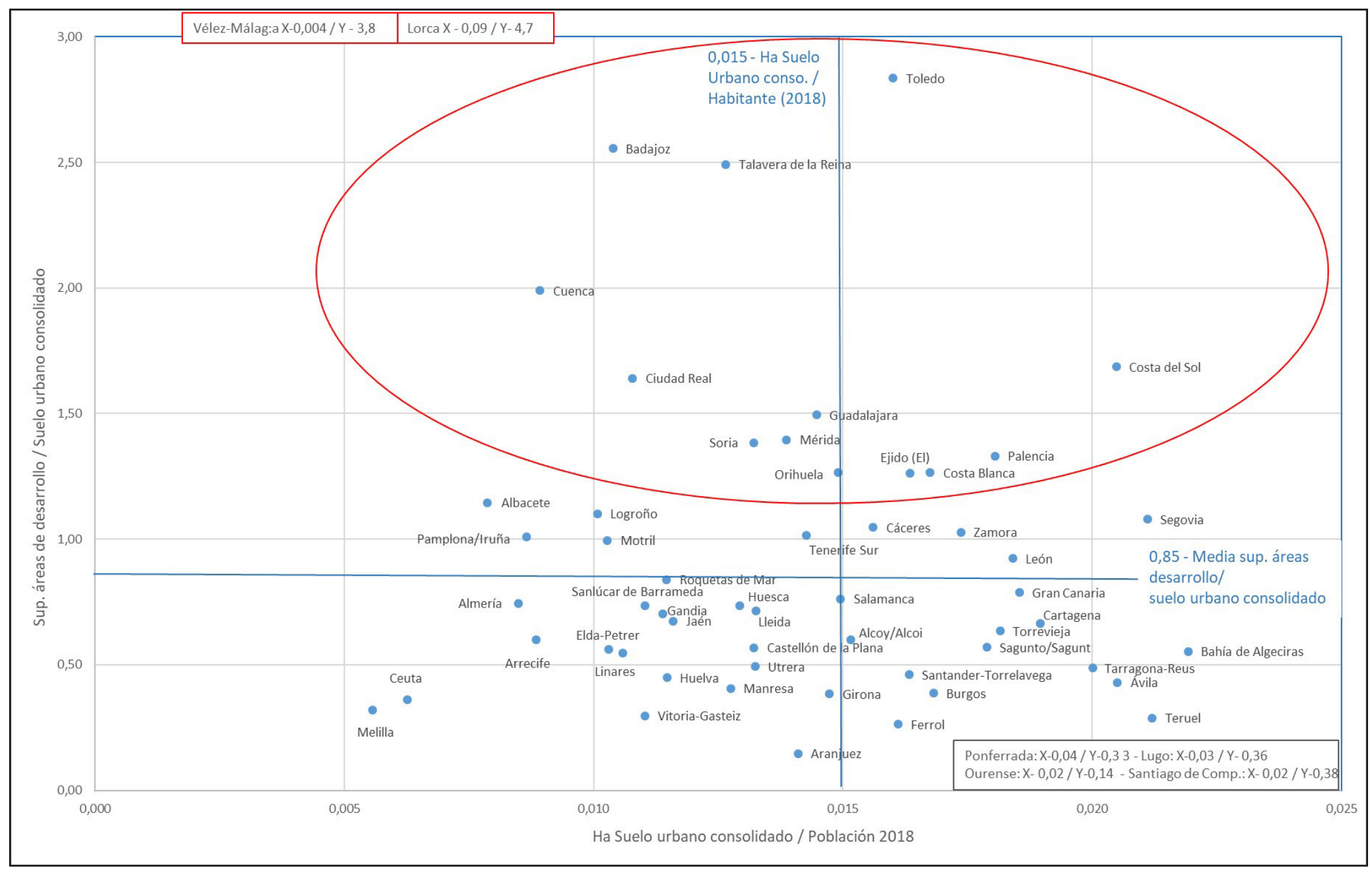

Fuente: Atlas Estadístico de las Áreas Urbanas del MTMA. 2018. Padrón Municipal de Habitantes 2018. Elaboración propia 
Figura 9. Expectativas de crecimiento en áreas de desarrollo según planeamiento vigente en las áreas urbanas articuladas por ciudades medias (2018). Superficie y número de viviendas previstas en nuevos desarrollos

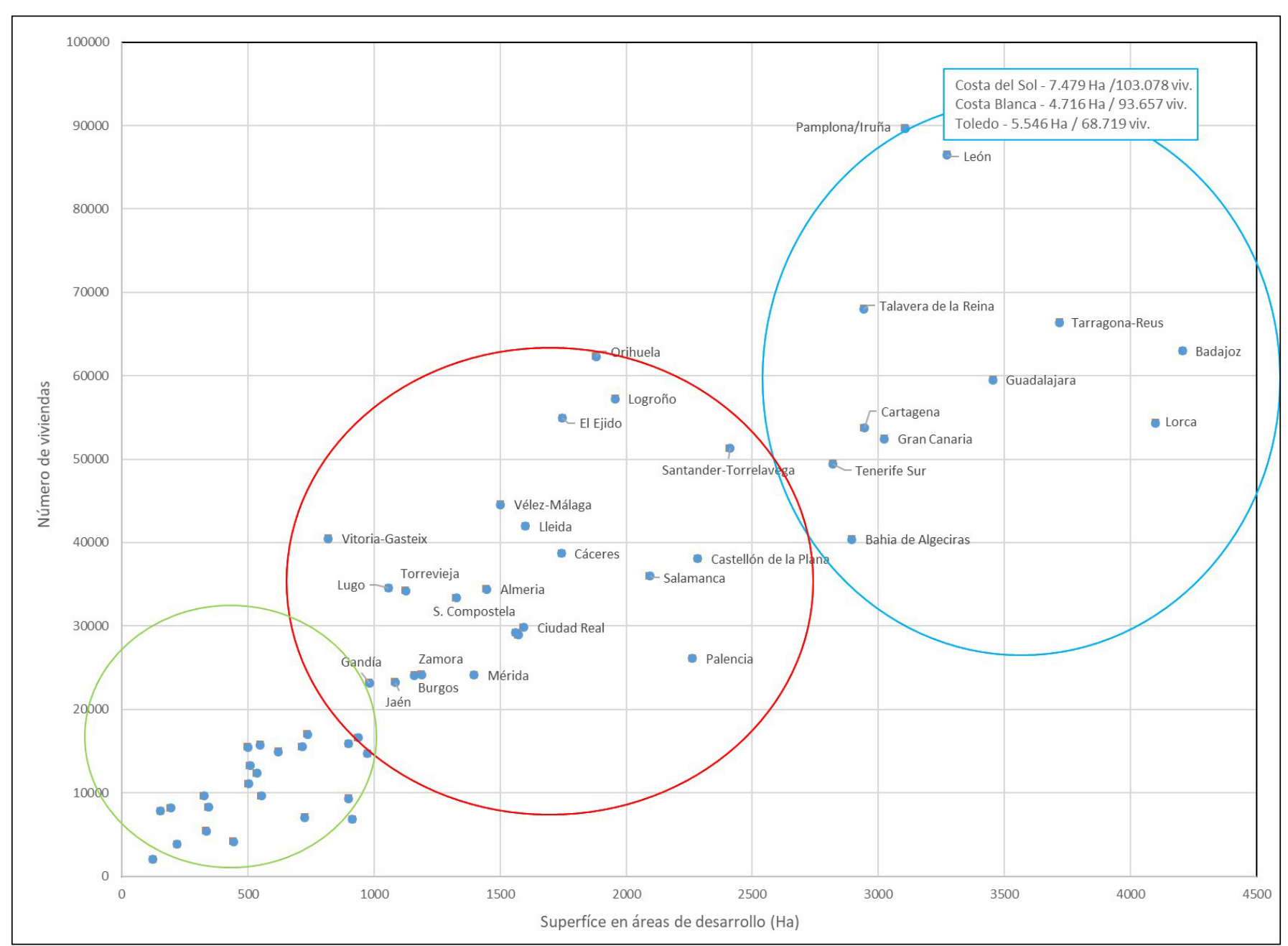

Fuente: Atlas Estadístico de las Áreas Urbanas del MTMA. 2018. Padrón Municipal de Habitantes 2018. Elaboración propia 
Estas cifras revelan la evidencia de que el discurso del urbanismo que modera los crecimientos no se refleja aún en el planeamiento de las ciudades medias españolas que sigue presentando en general el modelo expansivo del período anterior. Y abre una evidente discusión sobre las diferencias existentes entre las dinámicas reales de la urbanización reciente y las expectativas del posible desarrollo mediante nuevos sectores de desarrollo (suelo urbano no consolidado y suelo urbanizable) que permitirían continuar extendiendo aún más estas ciudades y sus áreas urbanas. A mediados de los años ochenta únicamente en ocho de las 60 áreas urbanas articuladas por ciudades medias se superaban las 3.000 ha de suelo urbanizado. En la actualidad, esa cifra se supera en 26 de las de las 60 áreas urbanas intermedias. Haciendo la misma comparativa, en 1981 solamente en siete de estas ciudades había más de 60.000 viviendas. Hoy en día, esta cifra se supera en 30 de las 60 áreas urbanas. El crecimiento y la fuerte extensión son por lo tanto manifiestos y hablan de un modelo urbano focalizado en los procesos de crecimiento que, en el actual contexto de crisis y evidente cambio de ciclo, genera incertidumbre, una tensión latente y una notable contradicción.

\section{Discusión}

Las evidencias del cambio de ciclo en el proceso urbanizador son muy claras analizando la información estadística que se ha considerado y repasando otras aportaciones que estudian la evolución del mercado inmobiliario. Tal y como indican las cifras, desde el año 2008 se abre una evidente paralización de los crecimientos que indica un cambio de tendencia. Durante la última década, las ciudades medias no crecen demográficamente y se han quedado claramente estancadas en su evolución, dado el parón inmigratorio. Al mismo tiempo, la crisis económica ha supuesto un intenso frenazo al proceso constructivo y a la expansión urbana. A partir del año 2008 en la práctica totalidad de áreas urbanas intermedias se han detenido los procesos de urbanización de nuevos ámbitos urbanos y la construcción se centra en la reforma interior de los espacios preexistentes y en la promoción de actuaciones en suelos urbanos no consolidados.

La situación general del mercado de la vivienda en España marca un claro hito, con el comienzo de un nuevo periodo que cierra una prolongada fase expansiva sustentada por los fuertes crecimientos económicos y las dinámicas hiper alcistas de los mercados en tiempos de bonanza (García, et al., 2020). Este cambio de ciclo deja atrás unas décadas de fortísimos crecimientos absolutos y relativos, que han redimensionado el sistema urbano y han relegado en muchos casos a posiciones secundarias las tradicionales fases predominantes del urbanismo desarrollista anterior. Muchas ciudades medias y sus áreas urbanas han crecido más desde 1980 de lo que habían crecido con anterioridad a lo largo de toda su evolución. Esta realidad del urbanismo expansivo ha puesto de manifiesto dos situaciones patológicas de este modelo urbano, acertadamente recogidas por Górgolas. Por una parte, el sobredimensionamiento del suelo urbanizable - recurrente y obsesivo, dice este autor-, como argumento de una planificación que siempre reclama más y más territorio para crecer. Y, por otra, la derivada contraria del abandono y olvido sistemático de la ciudad consolidada, en la que aún quedan muchos aspectos por resolver, incluida la materialización de una notable edificabilidad pendiente (Górgolas, 2019b).

En efecto, tras la explosión de la burbuja inmobiliaria en 2008 y la práctica paralización del sector se iría produciendo un cambio de rumbo de las políticas urbanísticas hacía una mayor contención en el desarrollo de suelo y una nueva mirada hacia el interior de la ciudad. Algunos de los planes generales de ordenación urbana aprobados en ciudades medias desde esta fecha contienen en su proyecto de ciudad y en su ideario urbanístico una clara apuesta por la contención de los crecimientos y una cierta vuelta al "urbanismo urbano" de los primeros ayuntamientos democráticos (Bellet, 2020). Sin embargo, el modelo de desarrollo urbano que cristalizó durante el "boom", lejos de haberse modificado, parece que continua latente en buena parte del planeamiento general de los municipios urbanos del país y la idea de un modelo urbano sostenible permanece más en los objetivos y la narrativa de los documentos que en la verdadera evidencia de sus propuestas de actuación.

Sin duda, el desajuste del urbanismo expansivo con la realidad de la dinámica social y económica de las ciudades medias y sus áreas ha generado fuertes contradicciones en un modelo que muestra graves problemas de sostenibilidad. Las áreas urbanas articuladas por ciudades medias que siguen presentando modelos basados en un planeamiento que apuesta por seguir creciendo y expandiendo la huella de la ciudad, se desalinean de las lógicas del urbanismo racional que se impulsa desde otras muchas instancias 
europeas e internacionales. Pese a los discursos sobre el regreso del "urbanismo urbano" o urbanismo de la crisis, las expectativas de crecimiento continúan siendo muy importantes en la mayor parte de estas ciudades. Algunos autores ya han identificado claramente que, en el marco de las grandes lógicas del capitalismo global, las grandes urbes inducen directamente el crecimiento del modelo económico y generan fuertes economías de escala. Pero esos mismos autores, han detectado también los graves problemas que ello ocasiona y han promulgado el papel que debe asignarse a las ciudades intermedias como nodos estratégicos para equilibrar el modelo urbano respecto a las deseconomías que producen las grandes ciudades en continúo y exponencial crecimiento (Frick y Rodríguez Pose, 2018).

Los fuertes desajustes y contradicciones del binomio crecimiento económico-extensión urbana están poniendo en primera línea de las reflexiones sobre el modelo de ciudad a las áreas urbanas intermedias. El planeamiento urbano, como ha ido ocurriendo en la historia reciente del urbanismo en España, reacciona tarde y no muestra una suficiente capacidad para adaptarse a las dinámicas y nuevos contextos urbanos. Las áreas urbanas se ordenan conforme a la idea de ciudad en un latente crecimiento, a la espera que cambie el ciclo económico y se produzca una nueva ola expansiva urbanizadora e inmobiliaria como la anterior. Pero las ciudades de esta escala urbana, bien conectadas y que cada vez presentan un sólido posicionamiento más allá de sus funciones como capitales administrativas, configuran nuevas polaridades y abren nuevas formas posibles de articulación dentro del sistema urbano. En dicho sentido, las políticas urbanísticas, más ágiles y concretas, necesitan extenderse y coordinarse con el planeamiento territorial y supramunicipal, al objeto de poder construir ciudades realmente más sostenibles y que no dependan únicamente de su capacidad de crecimiento (Capel, 2013b).

En dicho sentido, la apuesta de la planificación estratégica ha consolidado diversas funciones y perfiles de identidad en muchas de las áreas urbanas intermedias, que se han desarrollado como ciudades industriales, financieras, comerciales, turísticas, patrimoniales, etc. La opción del modelo de ciudad en virtud de sus verdaderos potenciales, sin una vinculación exclusiva sobre la expectativa del mero crecimiento residencial, está potenciando los atributos reales de las ciudades de esta escala urbana (conectividad, intermediación, interacción con el medio rural, articulación del territorio circundante, nodos de socialización y culturización, prestaciones de servicios y asistencia, etc.) con ejemplos no solo en España, sino también en el contexto de las redes urbanas de otras países (Torres, González y Manzano, 2020).

Es razonable considerar que es el momento de apostar por un decrecimiento de los procesos de urbanización, considerando nuevos modelos urbanos, revisando profundamente las lógicas de los planes de expansión y extensión que vienen aplicándose desde hace más de medio siglo en España. Desde esta perspectiva, se considera que es el verdadero momento de retomar los postulados de las Agendas Urbanas, suscritas en 2016 por Naciones Unidas y la UE y en 2018 por el Gobierno Español, en las que se manifestaba la necesidad de cambiar los patrones del modelo de urbanización para afrontar los principales retos del siglo XXI: cambio climático, problemas ambientales, inequidad y desigualdad social, despoblamiento de las áreas rurales, etc. Y, más si cabe, en el momento actual, en el que la alargada sombra de la crisis económica se ve sostenida por la grave y compleja crisis sanitaria provocada por la COVID19. En tales circunstancias vuelve a ponerse en cuestión el modelo urbano que en buena parte de las ciudades ha actuado como catalizador de los problemas provocados por este tipo de situaciones de riesgo: alta densidad, hipermobilididad, entornos no saludables y fuertes desigualdades en las condiciones de vida de las personas. En este contexto, las ciudades medias y más pequeñas vuelven a cobrar importancia, no sólo por su capacidad de reequilibrar el territorio, sino, además, porque muchas de ellas todavía conservan, al menos en sus núcleos centrales, los valores tradicionales que las referidas Agendas pretenden reforzar: su relativa compacidad, densidad, complejidad, su mezcla de usos y su tamaño medio, que las dota de una recomendable condición de ciudades domésticas para un mejor desarrollo de la vida cotidiana de las personas.

\section{Conclusiones}

Esta discusión y las reflexiones que la motivan están sin duda provocadas por las circunstancias analizadas en este trabajo, que conviene recapitular y concluir. Resulta evidente que las dinámicas de crecimiento urbano tuvieron un impacto notable en las áreas articuladas por ciudades medias (MAU) durante el periodo analizado. Se ha visto cómo, en términos relativos, las áreas urbanas intermedias son claramente la tipología de ciudad que más crece durante las últimas décadas en España. Su incremento demográfico en este periodo está 15 puntos porcentuales por encima de la media del conjunto de espacios 
urbanos y 21 puntos más que el de las grandes ciudades, presentando tendencias de crecimiento aún más acusadas en los casos de la vivienda (26 puntos porcentuales sobre la media y 39 sobre las grandes ciudades) y el suelo urbanizado (14 puntos porcentuales sobre la media y 24 sobre las grandes ciudades). Entre 1981 y 2018 el crecimiento inmobiliario y la expansión urbana en áreas urbanas intermedias duplica la ratio del incremento demográfico. En estas ciudades el espacio urbano se ha incrementado en un 86\% durante las últimas cuatro décadas. Cerca de la mitad de su suelo urbanizado es posterior a 1980. Las áreas urbanas articuladas por ciudades medias presentan las tasas de crecimiento relativo más intensas durante la fase expansiva del "boom" inmobiliario — con porcentajes de incremento anual de la vivienda y el suelo por encima del 3,1 y el $4,2 \%$, frente a 2,2 y 2,9 de las GAU-.

Se ha consolidado de este modo un modelo de expansión periférica como huella de un urbanismo expansivo que vincula el crecimiento económico al consumo de suelo. Los municipios menores de las áreas urbanas intermedias son los que experimentan de forma relativa los mayores crecimientos en las diferentes variables - frente al menor dinamismo de los municipios de las ciudades medias centrales-. $\mathrm{Y}$, además, este crecimiento en los municipios exteriores de las áreas urbanas se ha producido con un carácter menos denso y extenso en estos procesos de urbanización reciente. Todo ello ha modificado, en consecuencia, las estructuras urbanas tradicionales, más o menos compactas y densas de esas áreas, especialmente en las del interior peninsular.

Desde el año 2008 se ha abierto un cambio de ciclo muy notable en estas dinámicas de urbanización con un acusado estancamiento y una práctica paralización de todos los crecimientos que parece iniciar una cierta recuperación en 2015 detenida por la COVID19. La huella del urbanismo expansivo ha quedado paralizada con el final del "boom" inmobiliario y las tendencias sostenidas de crecimiento urbano vistas en las últimas décadas se han detenido o moderado. Se ha abierto así la discusión sobre el modelo urbano de la ciudad del siglo XXI, con una tendencia a considerar la necesidad de planificar ciudades más sostenibles en la escala intermedia. Sin embargo, el análisis del planeamiento urbanístico vigente demuestra que la planificación es continuista y, pese a la ruptura de las dinámicas de urbanización, continúa apostando por el crecimiento y la nueva producción urbana. Las expectativas del planeamiento urbanístico actual consideran la expansión de la ciudad existente en un amplio volumen de nuevo suelo en áreas de desarrollo que supondría hacer crecer a estas áreas urbanas intermedias en más de un 85\% sobre el actual suelo urbano consolidado. Estas previsiones tienen la capacidad para incrementar en casi un $50 \%$ el parque actual de viviendas, con lo que es evidente que el modelo sigue apostando por expandir el conjunto urbanizado.

En relación con estas conclusiones, el análisis desplegado ilustra la fuerte vinculación existente en el país entre crecimiento del sector de la construcción, modelos de urbanización y expectativas de crecimiento del planeamiento municipal para acabar configurando un modelo urbano expansivo, especulativo e insostenible, en el marco de lo que ha venido llamándose el capitalismo inmobiliario español. En España, el planeamiento y su ejecución se han ido convirtiendo en el instrumento básico para catalizar las expectativas de crecimiento económico, basadas, casi de forma exclusiva, en lo inmobiliario y en el consumo de suelo y de territorio - todo ello permitiendo la apropiación de plusvalías urbanas generadas desde lo colectivo y lo público-.

Con el despliegue definitivo del urbanismo neoliberal y la desregulación de los mercados financiero y de suelo, se produce la última fase expansiva del sector inmobiliario y de la construcción (1997-2007) que resulta en lo que se ha venido llamando el "tsunami urbanizador". Durante ese período se redactaron/ revisaron muchos documentos de planeamiento urbano municipales que continúan vigentes en muchos municipios españoles en la actualidad. Durante esos años, la "década prodigiosa del urbanismo español", el planeamiento recogió las expectativas que generaban las dinámicas de crecimiento expansivas y especulativas presentes en esos momentos. Se produce por tanto un claro desfase en los tiempos del planeamiento, dado que las expectativas de crecimiento que sostiene el planeamiento están muy por encima de lo que demanda la actual situación de contención y su previsión a medio plazo.

No parece posible, ni deseable mantener la idea de un urbanismo cuyo fundamento básico es ordenar el crecimiento sin fundamento demográfico y únicamente vinculado a la expectativa del crecimiento económico. El resultado es conocido: urbanización sin construcción, inmuebles y contenedores sin contenido ni uso; una ciudad vaga en su realización, por derivar de un plan sin fundamento ni más idea fuerza que la del crecimiento. 


\section{Financiación}

Esta contribución ha sido desarrollada en marco del desarrollo de los proyectos de investigación "Evolución de las políticas urbanísticas en ciudades medias españolas y sus áreas urbanas: 1979-2019 "(RTI2018-096435-B-C21) y "Procesos de cambio en la urbanización de las ciudades medias y sus áreas urbanas: 1979-2019" (RTI2018-096435-B-C22), financiados ambos por el Ministerio de Ciencia, Innovación y Universidades (España) - Proyectos I+D+i, en la convocatoria "Retos Investigación" de 2018.

\section{Referencias}

Adam, B. (2006). Medium-sized cities in urban regions. European Planning Studies, 14(4), 547-555. http:// dx.doi.org/10.1080/09654310500421220

Andrés, G. (2019). Las ciudades medias industriales en España. Evolución histórica, proceso de urbanización y estructura urbana. Ería. Revista Cuatrimestral de Geografía, 2019-1(Año XXXVIII), 25-49. https://doi.org/10.17811/er.1.2019.25-49

Andrés, G. (2020). Las ciudades medias industriales en España. Caracterización geográfica, clasificación y tipologías. Cuadernos Geográficos, 59(1), 99-125. http://dx.doi.org/10.30827/cuadgeo.v59i1.8225

Bellet, C. y Olazabal, E. (2017). Las ciudades intermedias en España. Dinámicas y procesos de urbanización recientes. En F. Maturana, M.E. Beltrão Sposito, C. Bellet, C. Henríquez, F. Arenas (Eds.), Sistemas urbanos y ciudades medias en Iberoamérica (pp. 144-181). Santiago de Chile: Instituto de Geografía Pontificia Universidad Católica de Chile.

Bellet, C. (2020). Las políticas urbanísticas municipales en España: 40 años de ayuntamientos democráticos (1979-2019). BAGE, (85). https://doi.org/10.21138/bage.2877

Burriel, E. (2008). La "década prodigiosa" del urbanismo español (1997-2006). En AAVV, Diez años de cambios en el Mundo, en la Geografía y en las Ciencias Sociales, 1999-2008. Actas del X Coloquio Internacional de Geocrítica. Recuperado de http://www.ub.edu/geocrit/-xcol/383.htm

Calderón, B. (2004). La ciudad del todo urbanizable: estrategias del sector inmobiliario y nuevas e insostenibles formas de urbanización. Revista Ciudades, 8, 135-155. Recuperado de https://dialnet. unirioja.es/servlet/articulo? codigo $=1253159$

Calderón, B. y García, J. L. (2017). Legislación urbanística y planeamiento urbano en España, 1998-2015. Del despilfarro a la sostenibilidad. Scripta Nova. Revista Electrónica de Geografía y Ciencias Sociales, 21, 570. https://doi.org/10.1344/sn2017.21.19429

Calderón, B. y García, J. L. (2018). La estructura de las ciudades españolas: un complejo entramado de relaciones entre permanencias y cambios, formas y usos. Boletín de la Asociación de Geógrafos Españoles, 77, 283-314. https://doi.org/10.21138/bage.2542

Capel, H. (2013a). La morfología de las ciudades. Vol. III: Agentes urbanos y mercado inmobiliario. Barcelona: Ediciones del Serbal.

Capel, H. (2013b). Crisis de los modelos urbanos. Una mirada hacia el futuro. Mercator, 2. Recuperado de http://www.mercator.ufc.br/mercator/article/view/1148

Cebrián, F. (2007). Ciudades con límites y ciudades sin límites: manifestaciones de la ciudad difusa en Castilla-La Mancha. BAGE, 262, 221-240. Recuperado de https://bage.age-geografia.es/ojs/index.php/ bage/article/view/589

Cebrián, F. (2013). Las transformaciones recientes operadas en las periferias de las ciudades medias. El contexto de la ciudad difusa en la realidad española. En F. Cebrián y M. Panadero (Eds.), Ciudades medias: formas de expansión urbana (pp. 25-38). Madrid: Biblioteca Nueva.

Cebrián, F. y Sánchez, I. (2019). Urban Sprawl in Inner Medium-Sized Cities: The Behaviour in Some Spanish Cases Since the Beginning of the 21st Century. Urban Science, 3(1). https://doi.org/10.3390/ urbansci3010010

Fernández, D. y Corbelle, E. (2017). Cambios en los usos de suelo en la Península Ibérica: Un metaanálisis para el período, 1985-2015. Biblio 3W, 22. https://doi.org/10.1344/b3w.0.2017.26442

Ferrer, A. y Solà-Morales, M. (2005). El urbanismo municipal en España. Papers. Regió metropolitana de Barcelona, 43. Recuperado de https://www.raco.cat/index.php/PapersIERMB/issue/view/7823 
Frick, S. y Rodríguez Pose, A. (2018). Big or Small Cities?. Growth and Change, 49(1), 4-32. https://doi. org/10.1111/grow.12232

Gaja, F. (2008). El "tsunami urbanizador" en el litoral mediterráneo. El ciclo de hiperproducción inmobiliaria 1996-2006. Scripta Nova. Revista Electrónica de Geografía y Ciencias Sociales, XII, 270(66). Recuperado de http://www.ub.edu/geocrit/sn/sn-270/sn-270-66.htm

Gaja, F. (2015). Urbanismo concesional. Modernización, privatización y cambio de hegemonía en la acción urbana. Revista Ciudades, 18, 1, 103-126. https://doi.org/10.24197/ciudades.18.2015.103-126

García, R., Serrano, J.M. y Espejo, C. (2020). The property sector in Spain. Evolutionary analysis, current problems and difficulties. Cuadernos Geográficos, 59(1), 6-31. https://doi.org/10.30827/cuadgeo. $\underline{\mathrm{v} 59 \mathrm{i} .7976}$

Gómez, J.M., Vieira, T. y Hernández, A. (2020). Procesos urbanos funcionales en Iberia: una aproximación a la integración del territorio urbano más allá de la metropolización. Cuadernos Geográficos, 59(2), 93-128. http://dx.doi.org/10.30827/cuadgeo.v59i2.9542

Górgolas, P. (2017). Burbujas inmobiliarias y planeamiento urbano en España: una amistad peligrosa. Cuadernos de Investigación urbanística-Ci[ur], 111,3-65. https://doi.org/10.20868/ciur.2017.111.3536

Górgolas, P. (2019a). La burbuja inmobiliaria de la "década prodigiosa" en España (1997-2007). Políticas neoliberales, consecuencias territoriales e inmunodeficiencia social. Reflexiones para evitar su reproducción. EURE, 45(136), 163-182. https://doi.org/10.4067/S0250-71612019000300163

Górgolas, P. (2019b). Del "urbanismo expansivo" al "urbanismo regenerativo": directrices y recomendaciones para reconducir la herencia territorial de la década prodigiosa del urbanismo español (1997- 2007). Aplicación al caso de estudio del litoral andaluz. Ciudad y Territorio. Estudios Territoriales, LI(199), 81-100. Recuperado de https://hdl.handle.net/11441/88016

Lois, R., Piñeira, M. J. y Vives, S. (2016). El proceso urbanizador en España (1990-2014): Una interpretación desde la geografía y la teoría de los circuitos de capital. Scripta Nova. Revista Electrónica de Geografía y Ciencias Sociales, XX, 539. https://doi.org/10.1344/sn2016.20.16793

López, L. (2014). Identificación y caracterización estratégica de las ciudades y aglomeraciones medias ibéricas. Ciudad y Territorio. Estudios Territoriales, 182, 625-649. Recuperado de https://apps.fomento. gob.es/CVP/handlers/pdfhandler.ashx?idpub=BP1010

López, I. y Rodríguez, E. (2010). Fin de ciclo. Financiarización, territorio y sociedad de propietarios en la onda larga del capitalismo hispano (1959-2010). Madrid: Traficantes Sueños.

Martínez Navarro, J. M., García González, J. A. y Escudero Gómez, L. A. (2020). Las ciudades medias de España y sus coronas en el siglo XXI (2000-2017): dinámica demográfica y desarrollo inmobiliario. Urbe. Revista Brasileira de Gestão Urbana, 12. https://doi.org/10.1590/2175-3369.012.e20190202

Méndez, R. (2018). La telaraña financiera. Una geografía de la financiarización y su crisis. Santiago de Chile: RIL-editores, Instituto de Geografía, Universidad Católica de Chile.

Ministerio de Transportes, Movilidad y Agenda Urbana (MTMA) (2018a). Atlas Digital de las Áreas Urbanas. Recuperado de https://www.mitma.gob.es/portal-del-suelo-y-politicas-urbanas/atlasestadistico-de-las-areas-urbanas

Ministerio de Transportes, Movilidad y Agenda Urbana (MTMA) (2018b). Sistema de Información Urbana (SIU). Recuperado de https://www.mitma.gob.es/portal-del-suelo-y-politicas-urbanas/sistema-deinformacion-urbana/sistema-de-informacion-urbana-siu

Miramontes Carballada, A. y Viera de Sá Marques, T. M. (2016). Las áreas urbanas en la península ibérica. Un ejercicio de delimitación. Papeles de Geografía, 62, 47-63. https://doi.org/10.6018/ geografia/2016/247681

Monclús, F. J. (1998). La ciudad dispersa. Barcelona: Centre de Cultura Contemporània de Barcelona.

Naredo, J.M (1996). La burbuja económico-financiera en la coyuntura económica reciente (1985-1995). Madrid: Siglo XXI de España.

Naredo, J.M. (2010). El modelo inmobiliario español y sus consecuencias. Boletín CF+S, 44, 13-27. Recuperado de http://habitat.aq.upm.es/boletin/n44/ajnar.html 
Olazabal, E. (2018). Dinámicas y caracterización del proceso de urbanización en España (1987-2011). Las áreas urbanas articuladas por ciudades medias (Tesis de Doctorado sin publicar). Departamento de Geografía y Sociología de la Universitat de Lleida. LLeida.

Olazabal, E. y Bellet, C. (2019). De la ciudad compacta a la ciudad extensa. Procesos de urbanización recientes en áreas urbanas españolas articuladas por ciudades medias. Anales de Geografía de la Universidad Complutense, 39(1), 149-175. https://doi.org/10.5209/aguc.64681

Pozueta J., Lamíquiz, P.J., Higueras, E. y Benito, M.(2019). The spatial dynamics of land use surrounding the Spanish property bubble (1990-2012). Investigaciones Regionales - Journal of Regional Research, 2019/3(45), 93-117. Recuperado de https://investigacionesregionales.org/es/article/the-spatialdynamics-of-land-use-surrounding-the-spanish-property-bubble-1990-2012/

Rodríguez, J. (2006). Los "booms" inmobiliarios en España. Un análisis de tres períodos. Papeles de Economía Española, 109, 76-90.

Romero, J., Brandis, D. y Melo, C. (2015). El giro neoliberal de las políticas para la ciudad en España. Balance a partir de los casos de Madrid y Valencia. BAGE, 69, 369-386. https://doi.org/10.21138/ bage.1901

Torres, M., González, Y. y Manzano, O. (2020). Marca ciudad como estrategia de competitividad urbana en las ciudades intermedias. Revista Espacios, 41(36), 171-185. Recuperado de http://www. revistaespacios.com/a20v4ln36/20413615.html

Vives, S. y Rullán, O. (2014). La apropiación de las rentas del suelo en España. BAGE, 65, 387-408. https:// doi.org/10.21138/bage.1758

Zúñiga, I. (2016). La forma del límite en las ciudades medias españolas. Cuadernos de Investigación Urbanística, (105), 1-66. Recuperado de http://polired.upm.es/index.php/ciur/article/view/3450 